\title{
Modelling the effects of climate change on air quality over Central and Eastern Europe: concept, evaluation and projections
}

\author{
Katarzyna Juda-Rezler ${ }^{1, *}$, Magdalena Reizer $^{1}$, Peter Huszar $^{2}$, Bernd C. Krüger ${ }^{3}$, \\ Prodromos Zanis ${ }^{4}$, Dimiter Syrakov ${ }^{5}$, Eleni Katragkou ${ }^{6}$, Wojciech Trapp ${ }^{7}$, \\ Dimitris Melas ${ }^{6}$, Hristo Chervenkov ${ }^{8}$, Ioannis Tegoulias ${ }^{4}$, Tomas Halenka ${ }^{2}$ \\ ${ }^{1}$ Faculty of Environmental Engineering, Warsaw University of Technology, 00-653 Warsaw, Poland \\ ${ }^{2}$ Department of Meteorology and Environment Protection, Charles University, 18000 Prague, Czech Republic \\ ${ }^{3}$ Institute of Meteorology, University of Natural Resources and Life Sciences, 1190 Vienna, Austria \\ ${ }^{4}$ Department of Meteorology and Climatology, Aristotle University of Thessaloniki, 54124 Thessaloniki, Greece \\ ${ }^{5}$ Department of Air and Water Pollution, National Institute of Meteorology and Hydrology, 1784 Sofia, Bulgaria \\ ${ }^{6}$ Laboratory of Atmospheric Physics, Aristotle University of Thessaloniki, 54124 Thessaloniki, Greece \\ ${ }^{7}$ Air Protection Unit of Ekometria, 80-299 Gdańsk, Poland \\ ${ }^{8}$ National Institute of Meteorology and Hydrology, Branch Plovdiv, 4000 Plovdiv, Bulgaria
}

\begin{abstract}
This paper presents regional scale simulations aiming to assess the sensitivity of future air quality under anticipated climate change, with a focus on near-surface ozone $\left(\mathrm{O}_{3}\right)$ and particulate matter with a diameter $<10 \mu \mathrm{m}\left(\mathrm{PM}_{10}\right)$. Constant anthropogenic emissions and biogenic emissions varying with climate were used. The modelling was carried out with regional climate models coupled to Chemical Transport Models for 3 decadal time slices, under the IPCC A1B scenario, in both coarse $(50 \mathrm{~km})$ and high $(10 \mathrm{~km})$ resolution for Europe and for targeted domains of Central-Eastern Europe (CEE), respectively. Two modelling systems were applied: the RegCM/CAMx and ALADINClimate/CMAQ driven by ECHAM5 and ARPEGE global climate models, respectively. A comprehensive 'operational' evaluation of the performance of modelling systems driven by re-analysis of ECMWF ERA-40 fields was carried out for one full year. Our modelling systems fulfilled the fractional bias (FB) and fractional error (FE) skill criteria and the benchmark of index of agreement (IA) for maximum daily running $8 \mathrm{~h}$ mean $\mathrm{O}_{3}$, with FBs ranging from +4 to $-11 \%$, FEs of 14 to $31 \%$ and IAs of 0.63 to 0.87 . The models' performance for annual, winter and daily mean $\mathrm{PM}_{10}$ was weaker, with FBs of -3 to $-49 \%$ and FEs of 38 to $66 \%$, but skill criteria for PM were met. Those results justified the use of proposed modelling systems for future time projections. The simulated changes in climate has rather weak impacts on the air quality of the mid-century (2041-2050). For the end-century (2091-2100), our study shows an increase in summer mean $\mathrm{O}_{3}$ and a decrease in annual mean $\mathrm{PM}_{10}$ in CEE. The main climate factors responsible for projected changes were an increase in summer temperature and a decrease in summer precipitation for $\mathrm{O}_{3}$, and an increase in winter precipitation for $\mathrm{PM}_{10}$.
\end{abstract}

KEY WORDS: Climate change $\cdot$ Air quality $\cdot$ Central-Eastern Europe $\cdot$ Regional modelling $\cdot$ Model evaluation · Future projection · Ozone $\cdot$ Particulate matter

\section{INTRODUCTION}

Global climate change is widely recognised as one of the most prominent challenges facing humankind today (EEA 2010), and the composition and chem- istry of the atmosphere are inherently connected to the climate system (Isaksen et al. 2009). Climate change may affect exposure to air pollutants in many ways. Change in temperature patterns affects both anthropogenic and natural air emissions. Global, 
regional and local weather patterns, including temperature, precipitation, clouds, atmospheric water vapour, wind speed, and wind direction, influence atmospheric chemical reactions and affect atmospheric transport and deposition processes as well as the rate of pollutant export from urban and regional environments to global scale environments and viceversa. Climate change may also affect exposure to air pollutants by changing the distribution and types of airborne allergens (Bernard et al. 2001). On the other hand, emissions of pollutants change the chemical composition of the atmosphere, which in turn has a feedback effect on the regional and global climate (Ramanathan \& Feng 2009).

Future air quality (AQ) is related to: (1) anthropogenic emissions, (2) natural emissions and land use, and (3) climate change. Analysis of climate-AQ interactions was initially at a global scale, based on fully coupled global chemistry-climate models (GCCMs) (Hauglustaine et al. 2005, Liao et al. 2006, Racherla \& Adams 2006) or Global Climate Models (GCMs) coupled to global Chemical Transport Models (CTMs) (Tagaris et al. 2007, Wu et al. 2008). A model ensemble approach, which is believed to improve the robustness of results, was also used at a global scale to study tropospheric ozone distributions, budgets, and radiative forcings (Stevenson et al. 2006).

To study climate effects on AQ at a regional scale, coupling of regional climate models (RCMs) with regional CTMs is required. For both scales, integration between GCM/RCM and CTM is usually conducted off-line using archived GCM/RCM meteorological fields (Jacob \& Winner 2009), but also on-line integration is used in some studies (e.g. Giorgi \& Meleux 2007). Although regional-scale modelling needs more detailed information on anthropogenic and natural emission inventories as well as information for their chemical boundaries from GCCMs, a number of recent studies address the regional scale future AQ, both for Europe (Szopa et al. 2006, Meleux et al. 2007, Hedegaard et al. 2008, Zlatev 2010) and North America (Steiner et al. 2006, Bell et al. 2007, Tagaris et al. 2007, Holloway et al. 2008, Nolte et al. 2008, Wu et al. 2008, Liao et al. 2009). Most of the studies dealt solely with ozone $\left(\mathrm{O}_{3}\right)$, some of them also with particulate matter (PM) (Racherla \& Adams 2006, Tagaris et al. 2007, Liao et al. 2009), while Hedegaard et al. (2008) simulated future levels of sulphur $\left(\mathrm{SO}_{2}\right)$ and nitrogen $\left(\mathrm{NO}_{2}\right)$ dioxides as well. Recently, Jacob \& Winner (2009) reviewed current knowledge of the effect of climate change on $\mathrm{AQ}$ with focus on 21st century projections for $\mathrm{O}_{3}$ and PM.
They found that all reviewed models show significant $\mathrm{O}_{3}$ increases in the northeastern USA and in Southern and Central Europe. Other regions show less consistency among the different models. At the same time they found that the effect of climate change on PM is more complicated and uncertain than for $\mathrm{O}_{3}$, with little consistency between studies, including the direction of the effect. While global-scale modelling is important for the $\mathrm{AQ}$ simulation to describe changes in background and in intercontinental transport of pollution, the spatial resolution of a few hundred $\mathrm{km}$ typical of global models (Stevenson et al. 2006) is inadequate to resolve small-scale meteorological features and chemical non-linearity relevant to AQ (Jacob \& Winner 2009). In contrast, RCMs have been applied at relatively higher spatial resolution ranging mainly between 10 and $60 \mathrm{~km}$ (Rummukainen 2010).

This study assesses newly developed modelling systems for studying climate change impacts on $A Q$, with a focus on near-surface $\mathrm{O}_{3}$ and $\mathrm{PM}_{10}$, assuming constant anthropogenic emissions. We set up a European wide domain for boundary conditions calculations (Krüger et al. 2008, Katragkou et al. 2010) and 4 targeted domains in Central-Eastern Europe (CEE). We used the RCM/CTM approach, where the CTM was integrated off-line with the RCM. The robustness of our modelling system for the European domain was shown by Katragkou et al. (2010) and Zanis et al. (2011), where $10 \mathrm{yr}$ of $\mathrm{O}_{3}$ simulations were performed for the present climate, comparing GCM-driven with reanalysis-driven (ERA-40) simulations. The projected effect of climate change on $\mathrm{O}_{3}$ levels in Europe for the end of century, simulated at $50 \mathrm{~km}$ resolution, was studied by Krüger et al. (2008) and Katragkou et al. (2011). The present study focuses on regional scale climate-AQ modelling in targeted regions of CEE for which, according to our knowledge, no studies have been conducted so far. We focus on average species concentrations, while the modelled changes in species exceedances in the regions under concern are discussed by Huszar et al. (2011).

\section{CONCEPTS AND METHODS}

The main objective of this paper is to evaluate climate change impacts on projected $\mathrm{AQ}$ in the target regions of CEE. To isolate the effect of climate change, constant anthropogenic emission is assumed for all simulations. We used the most frequent approach adopted for such an evaluation (Jacob \& Winner 2009, Rummukainen 2010), i.e. the future- 
minus-present method. This is based on the assumption that biases in simulated present-day and future climates tend to cancel each other, and thus their difference captures the signal of the concentration anomalies (Jimenez-Guerrero et al. 2011). In order to discern the climate change impacts from the interannual variability, we applied the Student's $t$-test for assessing the statistical significance of the obtained differences between future and present climate. As key species we chose $\mathrm{PM}$ and $\mathrm{O}_{3}$, which are air pollutants of utmost importance regarding human health (WHO 2007, 2008, EEA 2010).

\subsection{Modelling systems set-up}

The model resolutions used in this study can be basically classified into 2 categories: large-scale (LS) models with a horizontal resolution of $50 \times 50 \mathrm{~km}$, and fine scale (FS) models with resolutions of $10 \times 10 \mathrm{~km}$. The European domain was first established for background LS calculations (Katragkou et al. 2010). Then, 4 targeted FS domains were set-up in CEE, being centred over Czech Republic, Poland, Hungary and Bulgaria. Adopted modelling domains are displayed in Fig. 1, while Table S1 (in the supplement, www.intres.com/articles/suppl/c053p181_supp.pdf) gives an overview of the applied modelling systems set-up.

The GCMs simulations were driven by the A1B scenario of future greenhouse gases emissions, established by the International Panel on Climate Change (IPCC) Special Report on Emissions Scenarios (SRES) (Nakicenovic et al. 2000). They provided meteorological boundary conditions for targeted

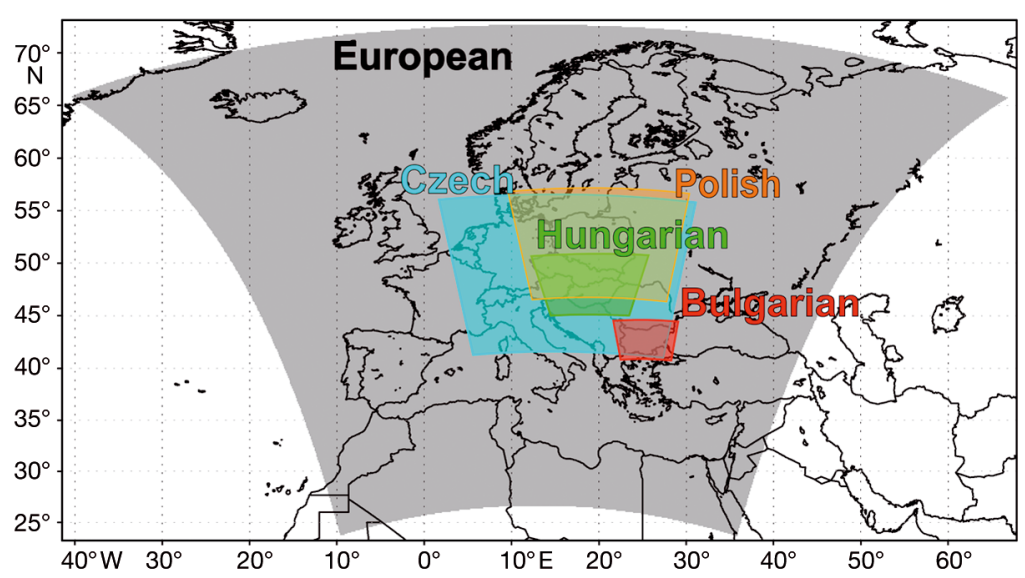

Fig. 1. Spatial coverage of the European and targeted domains used for the climate-air quality simulations with a horizontal resolution of 50 and $10 \mathrm{~km}$, respectively. The solid grey, blue, orange, green, and red polygons represent the European, Czech, Polish, Hungarian, and Bulgarian domains, respectively domain FS simulations, while chemical boundary conditions came from European LS CTMs. Changes in anthropogenic emissions were not introduced, as our goal was to study the effect of climate change solely. However, climate-sensitive biogenic emissions varied with the simulated climate. For the European domain as well as for the Czech, Polish and Hungarian domains, the RegCM3/CAMx modelling system driven by ECHAM5 GCM was implemented. The Bulgarian domain was computed by the ALADINClimate/CMAQ system, driven by ARPEGE GCM, as an alternative. The Czech domain dominates in size and encompasses almost all the other domains. Applying the same modelling system to Europe and to 3 targeted domains, we have a unique possibility to compare model results and evaluate model sensitivity to its configuration. With the use of one additional modelling system, we can further evaluate performance of different modelling approaches. We believe that such a modelling experiment helps to increase the robustness of the results.

To study anticipated climate impacts on $A Q$, simulations were performed for 3 decades: 1991-2000, 2041-2050, and 2091-2100. The present decade 19912000 was simulated twice, with different meteorological forcing: re-analysis ECMWF fields (ERA-40) and GCM driven control experiment. These 2 runs will be referred to hereafter as ERA and GCM control runs (CRs), respectively. The ERA-40 reanalysis project provides a global analysis of the state of the atmosphere, land and surface conditions over the period 1957-2002, based on assimilation of model results with observations and satellite data (Uppala et al. 2005). Thus, it can be considered that the ERA run is closer to real atmospheric conditions and is used as the reference, while the GCM CR provides a basis for comparison between present and future climates. Finally, 2 GCM driven runs were performed on the decades 2041-2050 and 2091-2100, which we will refer to as near future (NF) and far future (FF) decades, respectively.

A comparison of the driving climate parameters for the selected $10 \mathrm{yr}$ time slices (adopted in this study) with $30 \mathrm{yr}$ time slices usually adopted in climate studies, shows that the selected NF and FF decades are comparable with the $30 \mathrm{yr}$ time slices 2021-2050 and 20712100 , respectively (see Table 1). The climate parameters used for the comparison are near surface temperature, pre- 
Table 1. Average values over Europe $\left(10^{\circ} \mathrm{W}\right.$ to $30^{\circ} \mathrm{E}, 30^{\circ} \mathrm{N}$ to $\left.70^{\circ} \mathrm{N}\right)$ and Central-Eastern Europe $(\mathrm{CEE})\left(10^{\circ} \mathrm{E}\right.$ to $30^{\circ} \mathrm{E}, 40^{\circ} \mathrm{N}$ to $60^{\circ} \mathrm{N}$ ) for near surface temperature, surface down-welling shortwave flux (RSSD), and precipitation rate as simulated from the Global Climate Model ECHAM5-r3 for the 30 yr periods of near past (1971-2000), near future (2021-2050), and far future (2071-2100) as well as for the 10 yr time slices of near past (1991-2000), near future (2041-2050), and far future (2091-2100) adopted in this study for the climate-air quality simulations. The respective values for the near past time slices based on ERA-40 are also shown in parentheses

\begin{tabular}{|c|c|c|c|c|c|c|}
\hline \multirow[t]{2}{*}{ Period } & \multicolumn{3}{|c|}{ Europe } & \multicolumn{3}{|c|}{$\longrightarrow \mathrm{CEE}$. } \\
\hline & $\begin{array}{c}\text { Temperature } \\
\left({ }^{\circ} \mathrm{C}\right)\end{array}$ & $\begin{array}{l}\text { RSSD flux } \\
\left(\mathrm{W} \mathrm{m}^{-2}\right)\end{array}$ & $\begin{array}{l}\text { Precipitation } \\
\qquad\left(\mathrm{mm} \mathrm{d}^{-1}\right)\end{array}$ & $\begin{array}{c}\text { Temperature } \\
\left({ }^{\circ} \mathrm{C}\right)\end{array}$ & $\begin{array}{l}\text { RSSD flux } \\
\left(\mathrm{W} \mathrm{m}^{-2}\right)\end{array}$ & $\begin{array}{l}\text { Precipitation } \\
\quad\left(\mathrm{mm} \mathrm{d}^{-1}\right)\end{array}$ \\
\hline $1971-2000$ & $11.7(12.1)$ & 131.6 (138.1) & $1.73(1.51)$ & $10.3(9.5)$ & 118.0 (124.9) & $1.79(1.60)$ \\
\hline $1991-2000$ & $12.2(12.3)$ & $133.0(139.7)$ & $1.73(1.44)$ & $10.3(9.8)$ & $118.0(125)$ & $1.73(1.52)$ \\
\hline $2021-2050$ & 12.8 & 133.3 & 1.73 & 10.3 & 118.0 & 1.81 \\
\hline $2041-2050$ & 13.1 & 133.7 & 1.72 & 10.6 & 118.4 & 1.82 \\
\hline $2071-2100$ & 14.7 & 134.6 & 1.69 & 12.5 & 120.6 & 1.78 \\
\hline $2091-2100$ & 14.9 & 135.0 & 1.71 & 12.6 & 120.9 & 1.82 \\
\hline
\end{tabular}

cipitation and surface down-welling shortwave flux. From Table 1 it can be inferred that the selected decades are characteristic or typical for the respective longer $30 \mathrm{yr}$ time slices both for the European domain $\left(10^{\circ} \mathrm{W}\right.$ to $30^{\circ} \mathrm{E}, 30^{\circ} \mathrm{N}$ to $\left.70^{\circ} \mathrm{N}\right)$ and the $\mathrm{CEE}$ domain $\left(10^{\circ} \mathrm{E}\right.$ to $30^{\circ} \mathrm{E}, 40^{\circ} \mathrm{N}$ to $\left.60^{\circ} \mathrm{N}\right)$. This conclusion can be also derived from Fig. 2, which shows the evolution of the $10 \mathrm{yr}$ moving averages over the 21st century for CEE. From Fig. 2 and Table 1 the reasonable agreement in climate variability between GCM and ERA runs over the present climate (1961-2000) can be also inferred for all 3 parameters. domain consecutively. These GCM/RCM European simulations were performed under EU-FP6 project CECILIA (www.cecilia-eu.org). The simulation covers the period of 1960-2100, with the radiative forcing of SRES A1B scenario.

RegCM3 is the 3rd generation of a model originally developed by Dickinson et al. (1989) and Giorgi \& Bates (1989). The model uses dynamical core based on the hydrostatic version of the NCAR-PSU Mesoscale Model v. 5 (MM5) (Grell et al. 1994) and the radiative transfer package from the Community Climate Model v. 3 (CCM3). The LS cloud and precipitation

\subsection{Climatic simulations}

In our study 2 well-established RCMs were applied, namely: RegCM3 (Pal et al. 2007) and ALADIN-Climate (Farda et al. 2010). For assessing meteorological boundary conditions to RCMs, we used a double nesting approach based on the EU-FP6 project ENSEMBLES (http:// ensembles-eu.metoffice.com/) simulations. The ECHAM5 GCM (Roeckner et al. 2003) with $300 \mathrm{~km}$ resolution drove a Europe-wide version of RegCM3 with $25 \mathrm{~km}$ resolution, which in turn drove the RegCM3 with $10 \mathrm{~km}$ resolution applied in this study. The ARPEGE4 GCM (Déqué \& Piedelievre 1995) with a variable resolution of $50 \mathrm{~km}$ over southern Europe that decreases to $300 \mathrm{~km}$ at the antipodes was used to drive a European version of ALADIN-Climate with $50 \mathrm{~km}$ resolution, which drove the ALADINClimate $10 \mathrm{~km}$ version over Bulgarian

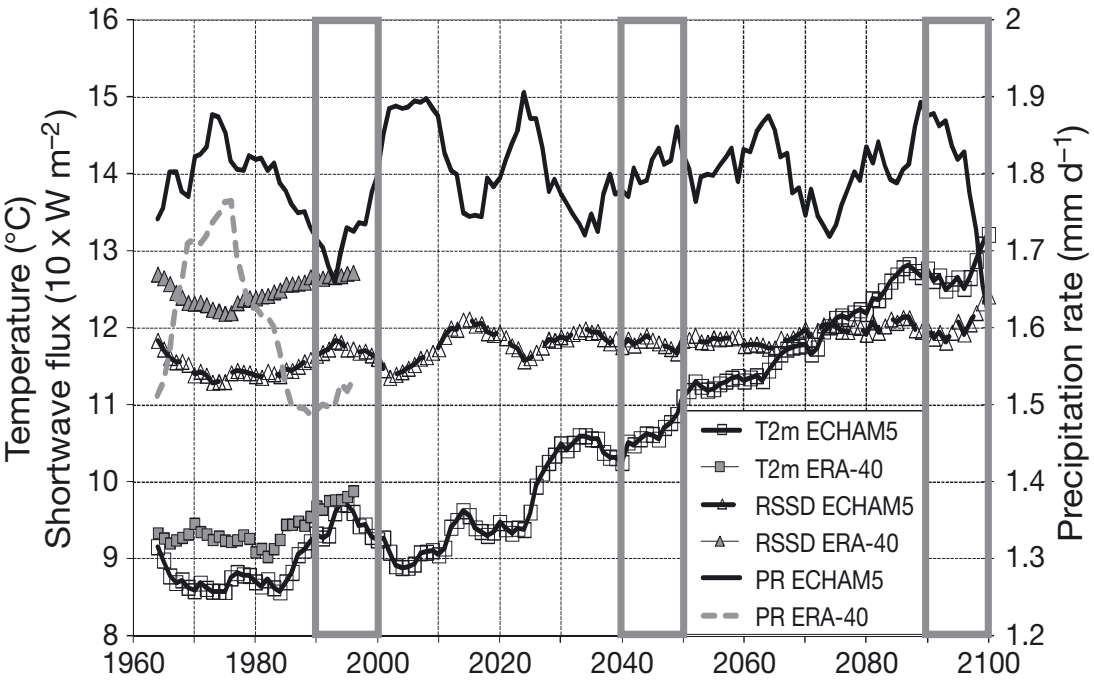

Fig. 2. Ten year moving average values over the Central-Eastern European domain $\left(10^{\circ} \mathrm{E}\right.$ to $30^{\circ} \mathrm{E}, 40^{\circ} \mathrm{N}$ to $\left.60^{\circ} \mathrm{N}\right)$ for near surface temperature (squares), surface down-welling shortwave flux (RSSD; triangles), and precipitation rate ( $P R$; solid line) as simulated from the global climate model ECHAM5-r3 from 1960 to 2100 under the SRES A1B scenario. The respective values from ERA-40 re-analysis are also shown for comparison (grey squares: near surface temperature; grey triangles: RSSD; grey dashed line: PR). Grey boxes: past and future time slices for which air quality experiments were carried out 
computations are done by the Subgrid Explicit Moisture Scheme (SUBEX). The schemes of Zeng et al. (1998) and Dickinson et al. (1993) are used for ocean surface fluxes and for the land surface physics (Biosphere-Atmosphere Transfer Scheme, BATS), respectively. The convective scheme adopted for our simulations is the Grell scheme (Grell, 1993) with the Fritsch \& Chappell (1980) closure assumption.

RegCM3 has been mostly applied to studies of regional climate and seasonal predictability around the world. A model version with improvements for fine resolution applications, namely the RegCM3-beta described by Torma et al. (2011), is used here for Czech, Hungarian and Polish domains.

The second RCM used is a hydrostatic version of ALADIN-Climate model, originally developed as the weather forecast limited area model by the international team headed by Météo-France and widely employed by various national meteorological services, particularly in CEE (Farda et al. 2010). ALADIN is a regional version of global model ARPEGE and uses the same dynamical core and physical parameterizations. For running ALADIN in climate mode, a few modifications had to be made, which mainly included changes in lower boundary condition specifications and availability of restart. ALADIN-Climate used in our study is described by Syrakov et al. (2010).

\subsection{Air quality simulations}

The AQ model simulations were carried out with the Comprehensive Air Quality Model with extensions (CAMx) (www.camx.com) for the majority of our domains and with Community Multi-scale Air Quality model (CMAQ) (www.cmaq-model.org) for Bulgarian domain. Both CAMx and CMAQ are stateof-the-art 3-dimensional CTMs, that have undergone continuous refinement by the science community over the past decade and are leading models used for policy and research applications related to ozone and aerosols (Morris et al. 2005a, Tesche et al. 2006). Both CTMs have been applied widely for a variety of short-term (e.g. Andreani-Aksoyoglu et al. 2008, Smyth et al. 2009, Pun et al. 2009, Fountoukis et al. 2011) and long-term (e.g. Morris et al. 2005a,b, Tesche et al. 2006, Appel et al. 2007, 2008, Lonati et al. 2010, Chemel et al. 2010) AQ modelling studies. Tesche et al. (2006) performed operational, diagnostic, and comparative evaluations of these 2 models for speciated fine PM across the eastern USA. They concluded that CMAQ and CAMx perform comparably for most species across the 2 domain resolutions tested (36 and $12 \mathrm{~km}$ ) and across all time scales, from $1 \mathrm{~h}$ to $1 \mathrm{yr}$. Both CTMs are public domain and have many similarities in conceptual formulation, numerical implementation, and operational usage. Our simulations were carried out for the 3 time-slices: 1990-2000, 2040-2050, and 2090-2100, with the first year used as a spin-up time.

CAMx v. 4.4 (ENVIRON 2006), was applied to European, Czech, Polish and Hungarian domains (see Table S1). The model uses mass conservative and consistent transport numerics in a parallel processing way. The chemistry mechanism invoked is Carbon Bond v. 4 (CB-IV) (Gery et al. 1989), that includes 117 reactions - 11 of which are photolytic - and up to 67 species (37 state gases, up to 18 state particulates and 12 radicals). For aerosol processes, the ISORROPIA thermodynamic equilibrium model (Nenes et al. 1998) is used. In our study, CAMx is off-line coupled to RegCM3 with an interface, which reads the basic meteorological parameters from RegCM3 and converts them into format accepted by CAMx. The same horizontal modelling grids with Lambert Conformal Conic map projection were used for RegCM3 and CAMx in order to avoid interpolations between grids. In vertical, $18 / 23$ vertical $\sigma$-levels were used in RegCM3, while CAMx is run over the lowermost 12 levels of varying thickness (see Table S1). Layer 1 is $36 \mathrm{~m}$ deep and the uppermost layer is $1.2 \mathrm{~km}$ thick extending to about $6.5 \mathrm{~km}$. The lateral chemical boundary conditions for the FS runs with CAMx were delivered by the LS European CAMx simulation (Krüger et al. 2008), while top boundary conditions for all gaseous species were kept constant, with no seasonal variation and annual variability; ozone was set to $40 \mathrm{ppb}, \mathrm{NO}_{2}$ to $1 \mathrm{ppb}$, and $\mathrm{CO}$ to $200 \mathrm{ppb}$. For European LS simulation the same constant values were adopted at both lateral and top boundaries. This implies that changes of these concentrations in the global background, that may be caused by changes of climate or other conditions, are not covered by this study. Also, impacts from potential changes in stratosphere/troposphere exchange as well as effects of long range transport of pollutants, which often takes place at tropospheric altitudes above the top of our grid (Trickl et al. 2003), are not considered here.

For the Bulgarian domain, AQ was simulated by a modelling system based on the US EPA Models-3 Community Modelling and Analysis System (CMAS) (Byun \& Schere 2006). The CMAS consists of: (1) CMAQ v. 4.6, the CTM; (2) MM5, the mesoscale meteorological model used as pre-processor to CMAQ, and (3) SMOKE, the emission model. For resolving 
chemistry, CB-IV upgraded with the ISORROPIA is used. The model simulates 78 pollutants, including 52 gases and radicals, 21 aerosols (Aitken and accumulation modes) and 5 aerosol distributions ( 3 by number, 2 by aerosol area). The vertical structure of CMAQ consists of $14 \sigma$-levels of varying thickness from which the first 8 represent the planetary boundary layer (PBL) (see Table S1). The model uses timeindependent chemical lateral boundary conditions for most species. In our study, the initial and boundary conditions were delivered by the LS CAMx calculations for the whole of Europe (Katragkou et al. 2010). The interface was developed for coupling offline ALADIN-Climate with CMAQ. More details concerning the Bulgarian modelling system is given by Syrakov et al. (2010).

\subsection{Anthropogenic emissions}

In order to exclusively study climate impacts on $A Q$, the anthropogenic emission in all simulations were kept constant at the values of the year 2000 for all considered time slices. For European LS simulations, the emission database is based on the European Monitoring and Evaluation Program (EMEP) inventory (Vestreng et al. 2007), available in gridded form on a $50 \times 50 \mathrm{~km}$ EMEP grid system based on a polar-stereographic projection. The inventory contains the annual totals of $\mathrm{CO}, \mathrm{NO}_{\mathrm{x}^{\prime}} \mathrm{SO}_{2}, \mathrm{NH}_{3}$, non-methane volatile organic compounds (NMVOC) and primary $\mathrm{PM}$, reported as fine $\mathrm{PM}_{2.5}$ particles (with aerodynamic diameter $<2.5 \mu \mathrm{m}$ ) and coarse $\mathrm{PM}_{10-2.5}$ particles $(2.5$ to $10 \mu \mathrm{m})$. Furthermore the emissions are distributed over 11 SNAP97 source sectors (Selected Nomenclature for sources of Air Pollution). SNAP97 is a standard defined by the CORINAIR guidebooks which ensures that emissions reported by different nations are comparable. These annual total emissions are further disaggregated in time and space. The temporal distribution is calculated via sector-dependent emission profiles from the inventory of Winiwarter \& Zueger (1996). For every sector, different distributions for the month, the day of the week and the hour of the day are applied. For the Pannonian countries (Austria, Czech Republic, Hungary, and Slovakia), the EMEP data are downscaled to a spatial resolution of $5 \times$ $5 \mathrm{~km}$. The emission inventory of Winiwarter \& Zueger (1996) for these countries is used as database for the spatial disaggregation of emission within the $50 \times 50 \mathrm{~km}$ grid cells. The resulting data are then converted to the common Lambertian pro- jection specified for our modelling domains. There is no vertical distribution of emission; the whole emission flux is assumed to be released into the surface layer as area source. Finally, the chemical speciation for $\mathrm{NO}_{\mathrm{x}}$ NMVOC and $\mathrm{PM}_{2.5}$ is elaborated, for compatibility with the CB-IV mechanism.

For Czech and Hungarian FS domains, as well as for part of the Polish domain excluding Poland itself, the emission database is elaborated in the same manner as for the LS simulation, however with the emission distribution at a spatial resolution of $10 \times 10 \mathrm{~km}$. For Poland, the emission model EMIL that follows a modular setup of the SMOKE model was developed (Trapp et al. 2010). Area, mobile, and point sources are calculated by different modules and merged into a single output file. For area (municipal, agricultural), mobile and small industrial sources (plants with a thermal input $\leq 50 \mathrm{MW}_{\text {th }}$ ), the model generates gridded 2D emissions. This is based on the following: a detailed emission sources inventory composed for the reference year 2000 at $1 \times 1 \mathrm{~km}$ resolution, meteorological and land-use data, population density, sector-specific activity, fuel demands and characteristics, and sector-dependent Polish specific emission factors. For Large Combustion Plants (LCPs) with a thermal input $>50 \mathrm{MW}_{\text {th }}$, a 3D emission database was created. It contains data for 220 stacks and consists of the emission and stack parameters. The vertical distribution is calculated in CAMx via Plume in Grid (PiG) algorithms using stack and meteorological data.

For the Bulgarian domain, the emission database is based on the Netherlands Organization for Applied Scientific research (TNO) high resolution $\left(0.25^{\circ} \times\right.$ $0.125^{\circ}$ ) inventory (Visschedijk \& van der Gon 2005). For LCPs, the specific effective height of pollutant release is assigned to a given SNAP category. Geographic information system software was applied to produce 3D emission field from TNO database. The temporal distribution was calculated via sectoral emission profiles from the LOTOS-EUROS emission model (Builtjes et al. 2003), where the temporal profiles are specific to country, pollutant, and sector. The speciation procedure for NMVOC and $\mathrm{PM}_{2.5}$ is done in accordance with CB-IV/ISORROPIA mechanism, based on US EPA speciation database.

\subsection{Biogenic emissions}

Biogenic emissions are calculated as a function of meteorological parameters and land-use categories, and thus vary with changing climate. Although changes in land use that might affect biogenic emis- 
sion may be expected in a future climate, we did not include such changes in our study and kept the landuse constant. We used the data from the terrain preprocessor of MM5 model (www.mmm.ucar.edu/ mm5). For the majority of our domains, biogenic emissions of isoprene and monoterpenes were calculated with the use of the RegCM-CAMx interface as a function of $2 \mathrm{~m}$ temperature, global radiation, and land-use categories, following the procedure proposed by Guenther et al. (1993). For the Bulgarian domain, the SMOKE emission model (Houyoux et al. 2000) creates biogenic emission data suitable for CMAQ. It is calculated by the use of the bottom-up model BEIS3 (Guenther et. al. 2000) on the basis of gridded land-use data and ambient meteorology provided by MM5.

\subsection{Model performance evaluation methodology}

Sound model performance evaluations are critical for any modelling exercise and many approaches for methods and criteria have been recommended (e.g. Willmott 1982, Juda 1986, Chang \& Hanna 2004, Boylan \& Russell 2006); however, standard evaluation procedures and performance criteria still do not exist. In this study we propose a common and inclusive 'operational' model performance evaluation methodology, which focuses on comparing model results with measurements of species concentrations for a specific time period. 'Operational evaluation' refers to the generation of statistics for the deviations between model predictions and observations and comparing their magnitudes to some selected criteria (Dennis et al. 2010).

\subsubsection{Statistical metrics}

We selected a set of statistical measures and graphical analyses, which could assess model skill in a comprehensive way. The set of proposed metrics consists of 5 groups: (1) bias measures: mean bias $(\mathrm{MB})$, normalized mean bias (NMB), and fractional bias (FB); (2) error measures: mean error (ME), fractional error (FE), and root mean square error (RMSE); (3) correlation measures: correlation coefficient (r) and index of agreement (IA); (4) measures of model variance: normalized standard deviation, referred as skill variance (SKVAR); and (5) measures of model spread: fraction of predictions within a factor of 2 of observations (FO2). The proposed metrics characterize the general uncertainties in modelling results and provide both actual (i.e. measured in either parts per billion by volume, ppbv, or $\mu \mathrm{g} \mathrm{m}^{-3}$ ) and normalized (\%) measures of model performance. They inspect both the averages and the variability of the predictions as compared to measurements. The fractional measures (FB, FE) normalize the bias and error for each model-observed pair by the average of the model and observation, and are readily used, as they perform symmetrically with respect to under and over-prediction. The FB and FE have the advantage of bounding the maximum bias and error and do not allow a few data points to dominate the metric; what is more, these metrics do not assume that observations are the absolute truth (Boylan \& Russell 2006). The FB ranges from $-200 \%$ to $+200 \%$ and FE ranges from $0 \%$ to $+200 \%$. These and other bias and error metrics (usually MB and RSME) have been widely used as measures of model performance (e.g. Morris et al. 2005b, Smyth et al. 2009, Chemel et al. 2010). However, when assessing model skill, the correlation measures are important as well. In addition to Pearson's standard correlation coefficient (r), the IA is both a relative and a bounded metric, and was proposed by Willmott (1982) as an alternative to $\mathrm{r}$. The IA, which is also known as the anomaly correlation, is a measure of how well the model represents the pattern of perturbations around a mean value. The definitions of applied metrics are provided in Appendix 1.

For $\mathrm{O}_{3}$ and $\mathrm{PM}$, different indices were analysed, as these pollutants differ according to their seasonal and daily distribution as well as impact characteristics. For $\mathrm{O}_{3}$, we inspected the maximum daily $8 \mathrm{~h}$ running mean (MDR8) concentrations, which are often associated with adverse health effects in epidemiologic studies (e.g. Bernard et al. 2001) and used for assessing attainment of the EU limit values for $\mathrm{O}_{3}$ (EU Directive 2008/50/EC). Predicted yearly distribution of MDR8 $\mathrm{O}_{3}$ levels were compared with observed values; the highest percentiles were observed in spring-summer due to photochemical activity. In contrast, PM has distinct seasonal variation, with significantly higher winter/autumn levels compared to spring/summer ones. Health-based standards for $\mathrm{PM}_{10}$ were established for both annual as well as daily mean levels. Thus, both annual and winter means as well as daily mean $\mathrm{PM}_{10}$ concentrations were inspected.

Calculations of the statistical metrics were supported by qualitative (graphical) analyses of the results: (1) quantile-quantile scatter plots (QQ plots) of observed versus predicted indices for $\mathrm{O}_{3}$ and $\mathrm{PM}_{10}$ showing 5th, 25th, 50th, 75th and 95th percentiles 
values, (2) average daily profiles of observed and predicted summer $\mathrm{O}_{3}$, and (3) yearly time series of daily means of observed and predicted $\mathrm{PM}_{10}$. We used QQ scatter plots (see e.g. Lonati et al. 2010), as from an operational evaluation perspective, the distributional comparisons of observed and predicted variables is a more appropriate alternative to comparisons of means (Dennis et al. 2010).

\subsubsection{Data for evaluation}

During the validation process of the Eulerian Grid models, values of point observations at a site are compared against predicted values averaged for the grid cell area. Therefore, not all existing site data could be used for model evaluation purposes. The site observations selected for comparison with modelling results are taken to be representative of the scale covered by the model, i.e. should be representative of the grid area climatic conditions, as well as for average AQ within the grid area. In addition, the usual requirement of temporal data completeness should be met, as well as the requirement of a statistically sufficient number of sites, covering the entire area of interest.

The concentrations of $\mathrm{O}_{3}$ and $\mathrm{PM}_{10}$ predicted by CAMx/CMAQ models were evaluated using year 2000 surface observations from the EMEP (www. emep.int) and AirBase (http://acm.eionet.europa.eu/ databases/airbase) databases. All EMEP sites are situated in rural areas, thus making the observational data suitable for comparison with the modelled species simulated by the regional scale CTMs; consequently, only rural sites were selected from the Airbase. Sites with altitudes higher than $1500 \mathrm{~m}$ were excluded. Finally, 46 sites from 6 European countries for $\mathrm{O}_{3}$ and 17 sites from 4 countries for $\mathrm{PM}_{10}$, were selected, fulfilling the criteria of $75 \%$ completeness of the data sets within a year. Their spatial distribution is displayed in Fig. 3.

All selected sites are located on the 'overlapping modelling domain', i.e. in the region covered by all appropriate modelling domains (see Fig. 1). These were European, Czech and Hungarian domains, and European, Czech, Hungarian and Polish domains for $\mathrm{O}_{3}$ and $\mathrm{PM}_{10}$, respectively. For our smallest Bulgarian domain, there are quite few stations, with no
EMEP site. Moreover, the automatic sampling sites operated by Bulgarian EPA are placed in the most polluted areas - big cities and industrial regionsand thus cannot be used for evaluation. Only one official background site exists: the Rojen peak, at which $\mathrm{O}_{3}$ measurement campaign took place during the whole year 2000 (Donev et al. 2002). Therefore, despite the fact that Rojen peak is a mountain site, we used it for evaluation purposes. Due to lack of any observation, $\mathrm{PM}_{10}$ could not be evaluated in the Bulgarian domain.

For more detailed evaluation, we chose $2 \mathrm{O}_{3}$ and 2 $\mathrm{PM}_{10}$ sites for which predicted and observed diurnal patterns for $\mathrm{O}_{3}$ and yearly time series for $\mathrm{PM}_{10}$ were compared. For $\mathrm{O}_{3}$ these are the Illmitz EMEP AT0002R site in Austria $\left(47^{\circ} 46^{\prime} \mathrm{N}, 16^{\circ} 46^{\prime} \mathrm{E}\right.$, altitude $117 \mathrm{~m}$ ) and the the Rojen peak site, in the Rhodope Mountains in Bulgaria $\left(41^{\circ} 41^{\prime} \mathrm{N}, 24^{\circ} 44^{\prime} \mathrm{E}\right.$, altitude $1750 \mathrm{~m})$, while for $\mathrm{PM}_{10}$, Melpitz atmospheric research site in Germany $\left(51^{\circ} 32^{\prime} \mathrm{N}, 12^{\circ} 54^{\prime} \mathrm{E}\right.$, altitude $87 \mathrm{~m}$ ) and Kuźnia rural AirBase site in Poland $\left(50^{\circ} 12^{\prime} \mathrm{N}, 18^{\circ} 37^{\prime} \mathrm{E}\right.$, altitude $\left.237 \mathrm{~m}\right)$ were used. The station in Illmitz, situated in northeastern Austria, $50 \mathrm{~km}$ from Vienna, is one of the longest operating EMEP sites. We took the Rojen peak site as representative of the elevated European locations. The Melpitz research station operated by Leibniz Institute for Tropospheric Research (IfT), is one of the longest running European PM observation sites, and can be regarded as representative of central European $\mathrm{PM}_{10}$ pollution (Fountoukis et al. 2011). In contrast, the Kuźnia site (southern Poland) is situated in a rural area with forested surroundings, but $40 \mathrm{~km}$ west of the highly industrialized Upper Silesia region, and can be regarded as representative of the more polluted CEE region.
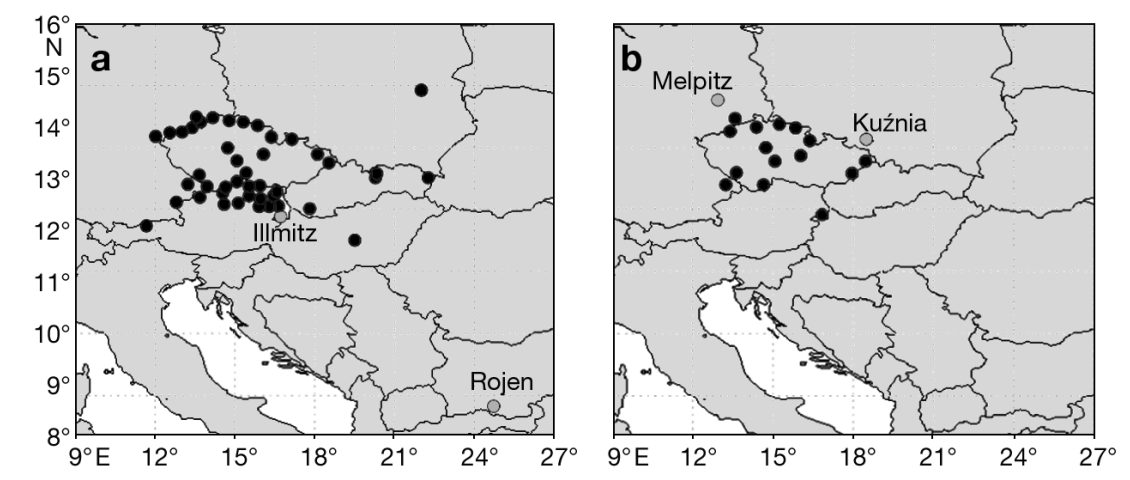

Fig. 3. (a) $\mathrm{O}_{3}$, and (b) $\mathrm{PM}_{10}$ monitoring sites used for the modelling systems evaluation. The displayed area corresponds to part of the Czech domain which overlaps with other domains (see Fig. 1). Grey dots indicate stations for which: daily $\mathrm{O}_{3}$ concentration profile averaged for summer (a) and yearly time-series of daily mean $\mathrm{PM}_{10}$ concentrations are compared with model predictions 


\section{RESULTS AND DISCUSSION}

\subsection{Evaluation of modelling systems performance for 2000}

For evaluation purposes, the simulations were performed for the calendar year 2000 (for which emissions were collected), with ERA-40 reanalysis fields to drive RCMs. Predicted values of the modelled variables were extracted from the first vertical layer of the modelling grids. It is worth noting that only a few published works actually report on performance characteristics of the regional AQ modelling systems for long-term simulations, especially for Europe (Chemel et al. 2010). Therefore, to our knowledge, this study provides the first 'operational' evaluation of a fine scale CAMx/CMAQ simulation for a yearlong run over Europe. One LS and 4 FS modelling systems (see Table S1 for overview of model set-ups) are evaluated.

\subsubsection{Ozone}

The quantile-quantile (QQ) scatter plots of the observed and predicted MDR8 mean $\mathrm{O}_{3}$ levels are presented in Fig. 4. Overprediction by more than a factor of 2 occurs mostly for $\mathrm{O}_{3}<10 \mu \mathrm{g} \mathrm{m}^{-3}$. For concentrations $>120 \mathrm{\mu g} \mathrm{m}^{-3}$, observations are underestimated by all our models.

These results are consistent with the findings of other published works reporting on performance characteristics of the CTMs for long-term simula- tions of $\mathrm{O}_{3}$. Analogous results were reported by Chemel et al. (2010), who simulated $\mathrm{O}_{3}$ over UK for the whole year 2003, and by Appel et al. (2007) from simulations over the eastern US for the year 2001. Comparison of the performance of our modelling systems also shows that they perform comparably well for 25th, 50th and 75th quantiles, while biases are bigger at the lower and upper end of $\mathrm{O}_{3}$ distribution, which is in agreement with the findings of Hogrefe et al. (2011). Furthermore, our European system underestimates observations to a greater extent than FS systems at the lower quantile, while the Czech system at the upper quantile. The lower percentiles of $\mathrm{O}_{3}$ distribution are more influenced by background pollution than the higher percentiles; hence the European system performs slightly worse for low $\mathrm{O}_{3}$ levels, due to lower resolution. Underestimation of peak values by the Czech system in comparison to the Hungarian and European ones was likely due to negative solar radiation bias that occurred in this system, resulting in a smaller $\mathrm{O}_{3}$ amplitude. To summarize, the models seem to display a typical annual cycle in performance. The lowest MDR8 mean $\mathrm{O}_{3}$ values are generally overpredicted, while maximum values are under-predicted. Similar findings have been reported by other authors (e.g. Honoré et al. 2008, Chemel et al. 2010). In addition, more detailed analysis taking into account separate day and nighttime values, reveals that CAMx performs considerably better during daytime (Katragkou et al. 2010). To illustrate diurnal performance of our models, daily profiles of the averages of predicted and observed surface $\mathrm{O}_{3}$ levels in sum-

Fig. 4. The quantile-quantile scatter plot of predicted versus observed percentiles (5th yellow; 25th green; 50th grey; 75th blue; 95th red) of maximum daily running $8 \mathrm{~h}$ mean $\mathrm{O}_{3}$ concentrations for the year 2000 . Predictions from different modelling systems are represented by different shapes (European: triangle; Czech: diamond; Hungarian: square). Dashed lines indicate the 1:1, 1:2 and 2:1 references

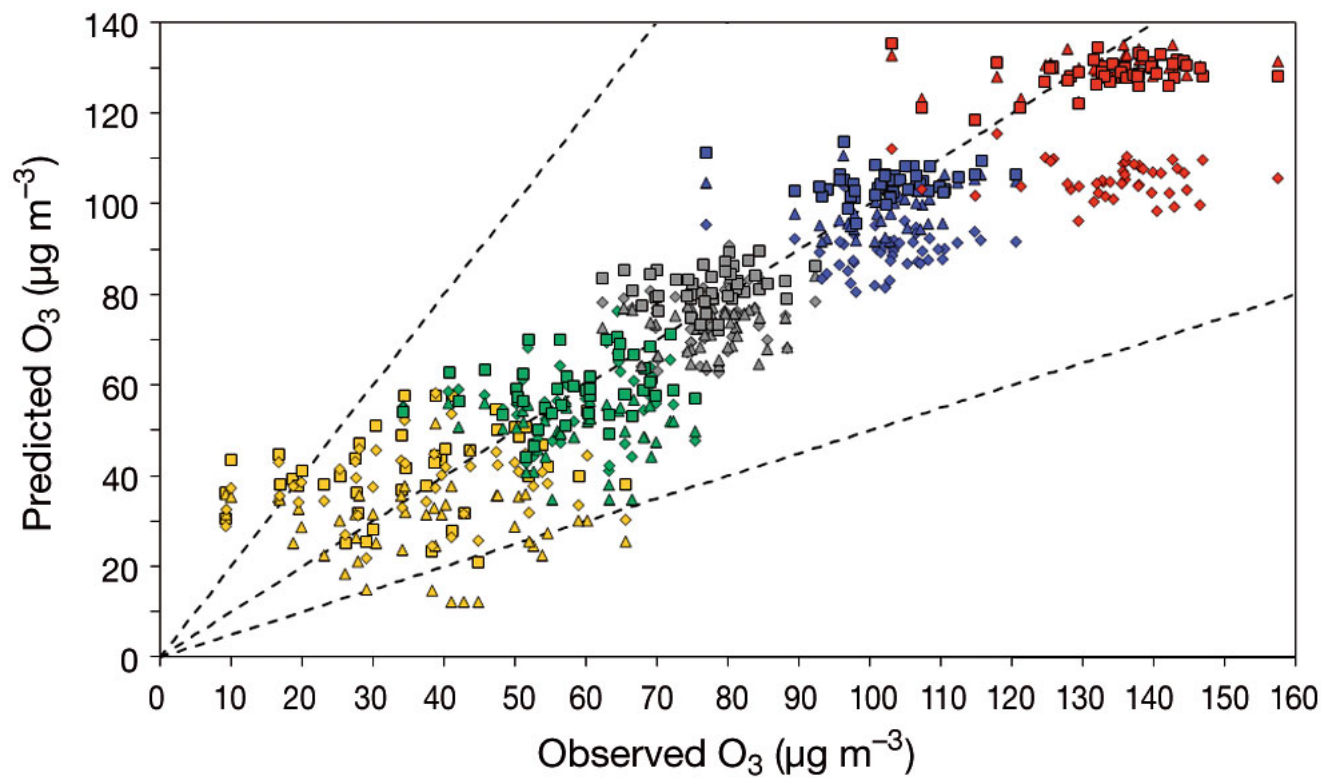



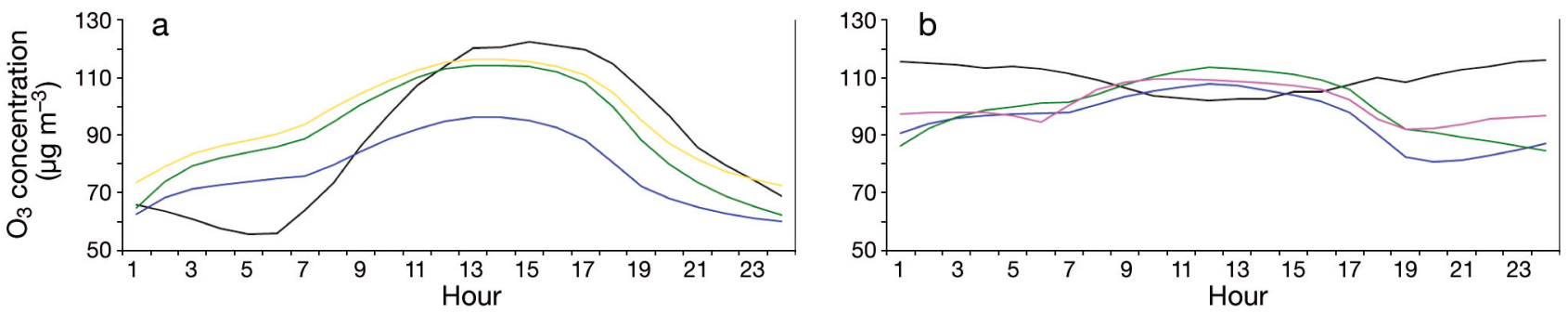

Fig. 5. Predicted versus observed daily summer $\mathrm{O}_{3}$ profile for the year 2000 at (a) Illmitz, Austria and (b) Rojen, Bulgaria monitoring sites (see Fig. 3 for the location of the stations). Solid black line: observations. Predictions from different modelling systems are represented by different colours (European: green; Czech: blue; Hungarian: yellow; Bulgarian: magenta)

mer (June, July, August), were calculated for 2 sites, and are shown in Fig. 5.

For the Illmitz EMEP site (Fig. 5a), all our models capture the shape of diurnal $\mathrm{O}_{3}$ cycle; however, the afternoon peak values are underestimated and display a phase lag of about $1 \mathrm{~h}$, while night minima are overestimated by 40 to $60 \%$. The greatest overestimation of peak value was obtained for the Czech domain $(\sim 20 \%)$. The daily course of $\mathrm{O}_{3}$ at the Rojen site reveals a typical profile for the mountain sites, with high levels (100 to $120 \mu \mathrm{g} \mathrm{m}^{-3}$ ) observed almost evenly throughout the day (Fig. 5b). Our models are quite able to capture this specific daily course; however instead of a slight decrease, which observations show around noon, they predict a slight increase and underestimate evening and nighttime $\mathrm{O}_{3}$ by about 20 to $30 \%$. In general, the nighttime $\mathrm{O}_{3}$ chemistry is difficult to simulate due to difficulties of modelling the evolution of the nocturnal boundary layer and its subsequent impact on surface $\mathrm{O}_{3}$ levels (Eder \& Yu 2006, Honoré et al. 2008). Furthermore, the observed concentrations represent near-surface conditions, while predicted ones are volume averages from the first vertical model layer ( 36 to $38 \mathrm{~m}$ in our simulations). During daytime, this layer is usually well-mixed; thus calculated $\mathrm{O}_{3}$ indices represent a near-surface state quite well. However, during night-time, the mixing layer is usually stable with uneven vertical structure, and thus modelled (average) levels are often overestimated (see Fig. 5a). The possible reason of this overestimation might also be related to underestimation of $\mathrm{O}_{3}$ deposition flux and/or underestimation of nighttime $\mathrm{O}_{3}$ titration. In mountainous areas, the climatic and anthropogenic conditions influencing $\mathrm{O}_{3}$ are quite specific. Due to lack of fresh emissions of $\mathrm{NO}$, local titration does not occur, while high levels are mainly connected with stronger daytime solar radiation and long-range transport of $\mathrm{O}_{3}$. Our predicted underestimation of evening and nighttime $\mathrm{O}_{3}$ (see Fig. 5b) might be connected with overestimation of $\mathrm{HO}_{\mathrm{x}}$ sinks in current CTM models, as it has been found recently in studies conducted near forested areas (Monks et al. 2009).

The results from scatter plots and daily profiles for $\mathrm{O}_{3}$ indicate satisfactory overall performance of all our models. However the Hungarian FS modelling set-up for central Europe and the Bulgarian FS model give the best qualitative results.

Table 2. Domain-wide statistics for maximum daily running $8 \mathrm{~h}$ mean $\mathrm{O}_{3}$ concentrations considering all predicted/observed pairs of values from all the sites within the 'overlapping' Central-Eastern European (CEE) domain and from the Rojen site within the Bulgarian/Czech domain. The statistical metrics are defined in Appendix A. EU, HUN, CZE, and BUL: European, Hungarian, Czech, and Bulgarian modelling systems, respectively; N and NS: number of sites and samples, respectively

\begin{tabular}{|c|c|c|c|c|c|c|c|}
\hline \multirow{2}{*}{$\begin{array}{l}\text { Statistical } \\
\text { metrics }\end{array}$} & \multirow[t]{2}{*}{ Unit } & \multicolumn{3}{|c|}{$\mathrm{O}_{3}$ (CEE domain) } & \multicolumn{3}{|c|}{$\mathrm{O}_{3}$ (CZE/BUL domain) } \\
\hline & & $\mathrm{EU}$ & HUN & CZE & EU & CZE & BUL \\
\hline $\mathrm{N}$ & - & 46 & 46 & 46 & 1 & 1 & 1 \\
\hline NS & - & 16017 & 16017 & 16017 & 326 & 326 & 326 \\
\hline Obs mean & $\mu \mathrm{g} \mathrm{m} \mathrm{m}^{-3}$ & 81.6 & 81.6 & 81.6 & 104.3 & 104.3 & 104.3 \\
\hline Pred mean & $\mu \mathrm{g} \mathrm{m}^{-3}$ & 76.5 & 83.2 & 73.1 & 93.4 & 97.6 & 97.8 \\
\hline$\sigma_{\mathrm{O}}$ & $\mu \mathrm{g} \mathrm{m}^{-3}$ & 31.4 & 31.4 & 31.4 & 21.4 & 21.4 & 21.4 \\
\hline$\sigma_{\mathrm{P}}$ & $\mu g \mathrm{~m}^{-3}$ & 32.1 & 28.7 & 22.0 & 20.1 & 13.6 & 14.7 \\
\hline SKVAR & - & 1.02 & 0.91 & 0.70 & 0.94 & 0.64 & 0.69 \\
\hline $\mathrm{MB}$ & $\mu \mathrm{g} \mathrm{m} \mathrm{m}^{-3}$ & -5.1 & 1.5 & -8.5 & -10.9 & -6.6 & -6.5 \\
\hline NMB & $\%$ & -6.2 & 1.9 & -10.4 & -10.5 & -6.6 & -6.2 \\
\hline $\mathrm{FB}$ & $\%$ & -7.9 & 3.6 & -7.6 & -11.2 & -5.3 & -5.4 \\
\hline $\mathrm{ME}$ & $\mu \mathrm{g} \mathrm{m}^{-3}$ & 19.2 & 16.1 & 22.1 & 15.2 & 16.4 & 14.1 \\
\hline $\mathrm{FE}$ & $\%$ & 29.1 & 23.2 & 31.0 & 16.2 & 16.2 & 14.4 \\
\hline RMSE & $\mu \mathrm{g} \mathrm{m}^{-3}$ & 24.2 & 20.5 & 27.8 & 18.7 & 20.5 & 16.6 \\
\hline $\mathrm{r}$ & - & 0.72 & 0.77 & 0.56 & 0.73 & 0.45 & 0.70 \\
\hline IA & - & 0.84 & 0.87 & 0.70 & 0.79 & 0.63 & 0.77 \\
\hline FO2 & $\%$ & 90.6 & 94.8 & 90.6 & 99.1 & 99.7 & 100.0 \\
\hline
\end{tabular}


The overall $\mathrm{O}_{3}$ performance statistics, proposed in Section 2.6 are given in Table 2 .

For the models overlapping domain, both European and Czech systems underpredict the MDR8 mean $\mathrm{O}_{3}$ levels. However, the European system underpredicts $\mathrm{O}_{3}$ to a lesser extent, with the MB of $-5.1 \mu \mathrm{g} \mathrm{m}^{-3}$ and NMB of $-6.2 \%$ vs. the MB of $-8.5 \mu \mathrm{g}$ $\mathrm{m}^{-3}$ and NMB of $-10.4 \%$ for the Czech system, while the FBs for the 2 systems are close $(-7.9 \%$ for the European system and $-7.6 \%$ for the Czech system). Moreover, the errors for the 2 systems are closely related, with comparable values of MEs of $19.2 \mu \mathrm{g}$ $\mathrm{m}^{-3}$ and $22.1 \mathrm{\mu g} \mathrm{m}^{-3}$, FEs of 29.1 and $31 \%$, and RMSEs of $24.2 \mu \mathrm{g} \mathrm{m}^{-3}$ and $27.8 \mathrm{\mu g} \mathrm{m}^{-3}$ for the European and Czech systems, respectively. Correlation coefficient as well as IA are higher for European system: 0.72 and 0.84 , respectively, vs. 0.56 and 0.70 for Czech system. The best performance is obtained from the Hungarian system, which slightly overpredicts the MDR8 $\mathrm{O}_{3}$ mean levels, with the MB of $1.5 \mu \mathrm{g}$ $\mathrm{m}^{-3}, \mathrm{NMB}$ of $1.9 \%, \mathrm{FB}$ of $3.6 \%, \mathrm{ME}$ of $16.1 \mu \mathrm{g} \mathrm{m}^{-3}$, FE of $23.2 \%$, RMSE of $20.5 \mu^{-3} \mathrm{~m}^{-3}, \mathrm{r}$ of 0.77 , and IA of 0.87 (see Table 2). A recent study by Chemel et al. (2010) reported comparable values for the WRF/ CMAQ modelling system over the UK for the whole year 2003 (MB of $3.3 \mathrm{\mu g} \mathrm{m}^{-3}, \mathrm{NMB}$ of $5.3 \%, \mathrm{FB}$ of $5.0 \%, \mathrm{ME}$ of $15.4 \mathrm{\mu g} \mathrm{m}^{-3}, \mathrm{FE}$ of $24 \%$, RMSE of $20.9 \mu \mathrm{g} \mathrm{m}^{-3}$, $\mathrm{r}$ of 0.69 , and IA of 0.97). For the Bulgarian domain all modelling systems slightly underestimate observations, however almost all predictions are within FO2 boundaries. The smallest biases and errors are obtained by the Bulgarian system, with values of $\mathrm{MB}$ of $-6.5 \mu \mathrm{g} \mathrm{m} \mathrm{m}^{-3}, \mathrm{NMB}$ of $-6.2 \%$, FB of $5.4 \%, \mathrm{ME}$ of $14.1 \mathrm{\mu g} \mathrm{m}^{-3}$, FE of $14.4 \%$, and RMSE of $16.6 \mu \mathrm{g} \mathrm{m}^{-3}$. Correlation and variance measures are slightly lower than those from European system, but still have satisfactory values of 0.7 (r), 0.77 (IA) and 0.69 (SKVAR).
Morris et al. (2005b) proposed model performance goals for $\mathrm{O}_{3}$ based on the FB and FE values. All our models fulfil the skill criteria of $\mathrm{FB} \leq 15 \%$ and $\mathrm{FE}$ $\leq 35 \%$, considered as 'excellent' by these authors as well as the IA benchmark of 0.6 , which is regarded as an indicator of good model performance (see for instance Gilliam et al. 2006). In addition, the SKVAR, which varies between 0.64 to 1.02 in our models, indicates that the variation of amplitudes between model predictions and observations are closely related. The evaluation results show that Hungarian and Bulgarian modelling systems perform better for $\mathrm{O}_{3}$ than both European and Czech modelling systems, although, the differences in performance between them are not large and can be difficult to explain. The Hungarian system is built with the same models (RegCM3/CAMx) as the European and Czech ones, and the forcing GCM is also the same. Other details concerning model set-up are very similar as well (see Table S1). Thus, the differences in model performance in CEE could arise from (1) horizontal model resolution, (2) domain size, and (3) anthropogenic emission data. Other authors have shown that for $\mathrm{O}_{3}$, model resolution does not influence results significantly. When comparing 6 different modelling systems under the CityDelta project in Europe, Vautard et al. (2007) did not find the expected improvement due to higher resolution in case of $\mathrm{O}_{3}$. Thus it is most probable that better performance is associated with higher quality emission data that were worked out successfully for our smaller domains. Moreover, our study suggests that the domain size (Hungarian vs. Czech domain) influences model performance and that FS climate-AQ modelling systems perform better in smaller, targeted domains. This is also true for our southern-eastern European region, although another modelling system was used there (ALADIN-Climate/CMAQ).
Fig. 6. The quantile-quantile scatter plot of predicted versus observed percentiles (5th yellow; 25th green; 50th grey; 75 th blue; 95 th red) of daily mean $\mathrm{PM}_{10}$ concentrations for the year 2000. Predictions from different modelling systems are represented by different shapes (European: triangle; Czech: diamond; Hungarian: square; Polish: circle). Dashed lines: 1:1, 1:2 and 2:1 references

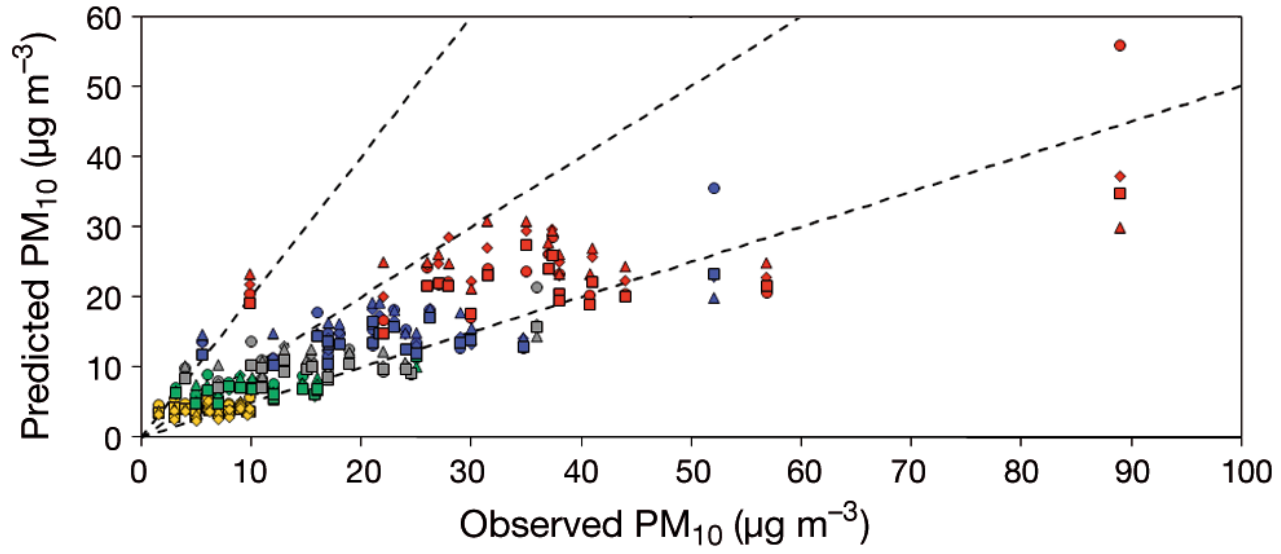




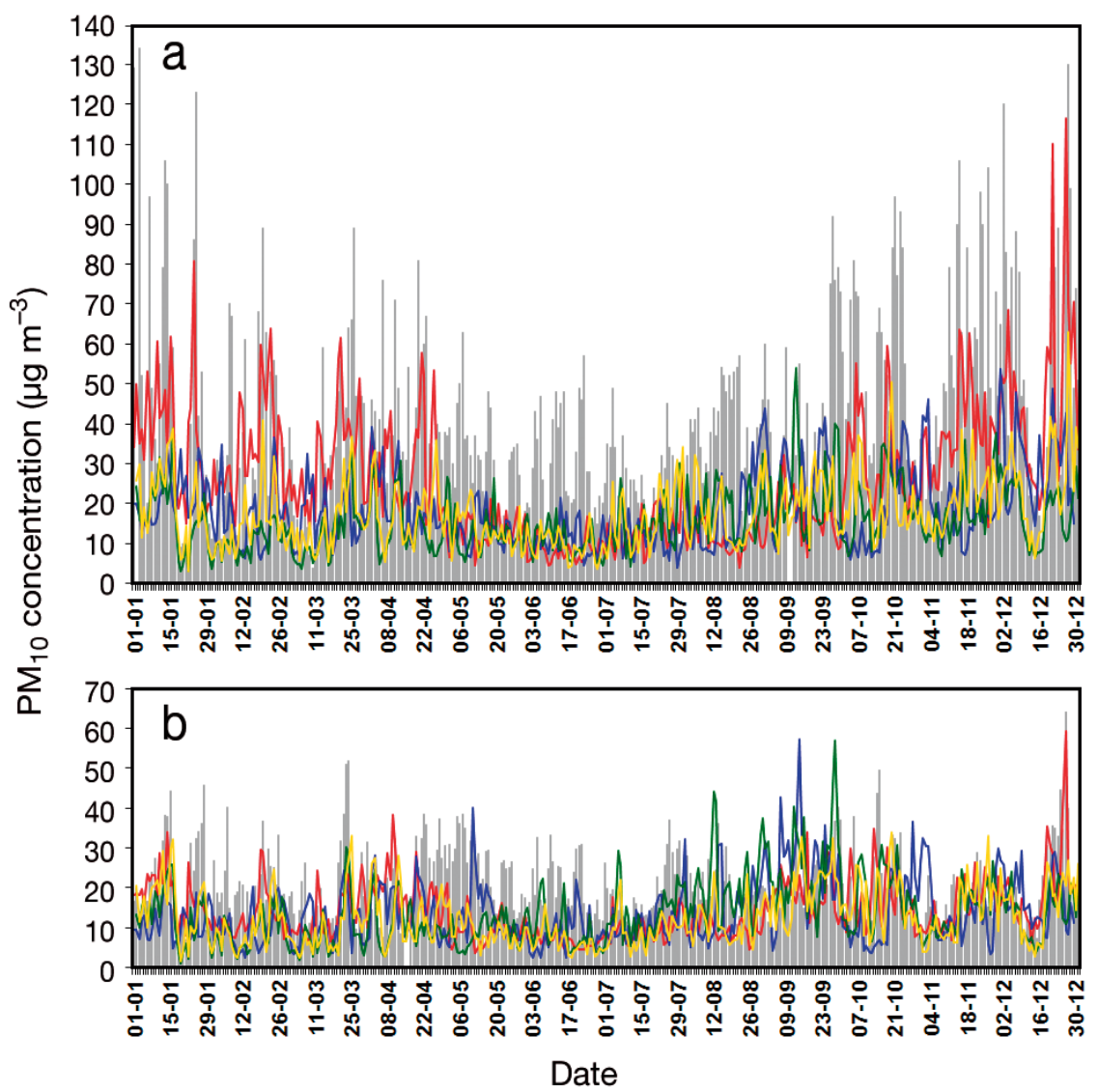

Fig. 7. Time series of observed (grey bars) and predicted daily mean $\mathrm{PM}_{10}$ concentrations at (a) Kuźnia and (b) Melpitz sites during the whole year 2000 (dates given as dd.mm; see Fig. 3 for the location of the stations). Predictions from different modelling systems are represented by different colours (European: green; Czech: blue; Hungarian: yellow; Polish: red)

Comparison of the results obtained for Bulgarian domain suggests also that CAMx and CMAQ models perform in a comparable way for $\mathrm{O}_{3}$. However, one has to be aware that model performance evaluation for Bulgarian domain is based on observations from one (untypical) monitoring site, which obviously limits the above finding.

\subsubsection{Particulate matter}

The ability of our models to simulate PM distribution is assessed qualitatively in Fig. 6 and Fig. 7, where the QQ scatter plot and yearly time series of the observed and predicted daily mean $\mathrm{PM}_{10}$ concentrations are presented, respectively.

The QQ scatter plot shows that all our models underestimate $\mathrm{PM}_{10}$ levels at all presented quantiles. These results are consistent with the findings of Lonati et al. (2010), who applied the CAMx model for year-long PM simulation over the highly polluted Po Valley in Italy, with a $10 \mathrm{~km}$ spatial resolution. In spite of overall underestimation of $\mathrm{PM}_{10}$, the Polish modelling system is, however, able to predict the cases of high concentration. This might be explained by the detailed emission inventory and the application of a sub-grid simulation of the plume from LCPs in the set-up of this modelling tool. In Fig. 7, the time series of observed and predicted daily mean $\mathrm{PM}_{10}$ values for Melpitz and Kuźnia sites under different anthropogenic pressures are shown for 'cold' (January-March and October-December) as well as for 'warm' (April-September) seasons of the year.

As it was described in Section 2.6.2, the IfT site in Melpitz represents the background pollution in central Europe, while Kuźnia site represents the highly polluted industrial region. This difference is clearly shown in our results, as both observed and predicted levels, especially for the 'cold' season, are significantly higher for Kuźnia. In general, the PM levels in winter/ autumn are considerably higher than in spring/summer in CEE, due to intense coal combustion as well as increased traffic emissions during unfavourable winter driving conditions. These sources were shown to play an important role in wintertime episodes of $\mathrm{PM}_{10}$ pollution across this region (Hoek et al. 1997, Pastuszka et al. 2010, Juda-Rezler et al. 2011). It can be noted that during the 'cold' season, observed daily levels at Kuźnia (Fig. 7a) site often exceed the EU limit value of $50 \mu \mathrm{g} \mathrm{m}^{-3}$. In addition, there are 13 cases in which high levels of $\mathrm{PM}_{10}$ exceed $80 \mu \mathrm{g} \mathrm{m}^{-3}$, with the highest value at $134 \mu \mathrm{g}$ $\mathrm{m}^{-3}$ on 3 January 2000 . This high variability of daily levels during the 'cold' season is reconstructed only by the Polish modelling system. Although predicted concentrations are much lower than those observed, the system is able to predict exceedances that actually occurred (with the exception of the end of October). At the same time, it should be pointed out that none of our modelling systems simulated a 'false alarm', i.e. exceedance that is predicted by model but does not actually occur. In Melpitz (Fig. 7b), the $\mathrm{PM}_{10}$ concentration in 'cold' season are much smaller, with the limit value exceeded only few times. All the mod- 
Table 3. Domain-wide statistics for annual, winter and daily mean $\mathrm{PM}_{10}$ concentrations considering all predicted/observed pairs of values from all the sites within 'overlapping' Central-Eastern European domain. The statistical metrics are defined in Appendix A. EU, HUN, CZE, POL indicate the European, Hungarian, Czech, and Polish modelling systems, respectively; N and NS read for number of sites and samples, respectively

\begin{tabular}{|c|c|c|c|c|c|c|c|c|c|c|c|c|c|}
\hline \multirow{2}{*}{$\begin{array}{l}\text { Statistical } \\
\text { metrics }\end{array}$} & \multirow[t]{2}{*}{ Unit } & \multicolumn{4}{|c|}{$\mathrm{PM}_{10}$ annual mean } & \multicolumn{4}{|c|}{$\mathrm{PM}_{10}$ winter mean } & \multicolumn{4}{|c|}{$\mathrm{PM}_{10}$ daily mean } \\
\hline & & EU & HUN & CZE & POL & EU & HUN & CZE & POL & EU & HUN & CZE & POL \\
\hline $\mathrm{N}$ & - & 17 & 17 & 17 & 17 & 17 & 17 & 17 & 17 & 17 & 17 & 17 & 17 \\
\hline NS & - & 17 & 17 & 17 & 17 & 17 & 17 & 17 & 17 & 5980 & 5980 & 5963 & 5996 \\
\hline Obs mean & $\mu \mathrm{g} \mathrm{m}^{-3}$ & 19.2 & 19.2 & 19.2 & 19.2 & 17.9 & 17.9 & 17.9 & 17.9 & 18.2 & 18.2 & 18.2 & 18.2 \\
\hline Pred mean & $\mu \mathrm{g} \mathrm{m}^{-3}$ & 12.7 & 11.0 & 12.0 & 12.3 & 13.5 & 12.8 & 12.8 & 15.5 & 12.7 & 11.1 & 12.0 & 12.4 \\
\hline$\sigma_{\mathrm{O}}$ & $\mu \mathrm{g} \mathrm{m}^{-}$ & 7.5 & 7.5 & 7.5 & 7.5 & 12.2 & 12.2 & 12.2 & 12.2 & 13.2 & 13.2 & 13.3 & 13.3 \\
\hline$\sigma_{\mathrm{P}}$ & $\mu \mathrm{g} \mathrm{m}^{-3}$ & 1.5 & 2.2 & 2.2 & 3.8 & 1.6 & 3.1 & 3.3 & 7.0 & 7.3 & 6.4 & 7.2 & 7.8 \\
\hline SKVAR & - & 0.20 & 0.29 & 0.29 & 0.50 & 0.13 & 0.25 & 0.27 & 0.58 & 0.55 & 0.48 & 0.54 & 0.58 \\
\hline MB & $\mu \mathrm{g} \mathrm{m}^{-3}$ & -6.6 & -8.2 & -7.3 & -6.9 & -4.5 & -5.1 & -5.1 & -2.4 & -5.5 & -7.1 & -6.2 & -5.8 \\
\hline NMB & $\%$ & -34.1 & -42.8 & -37.8 & -35.8 & -24.4 & -28.4 & -28.6 & -13.7 & -30.2 & -39.3 & -34.1 & -31.9 \\
\hline FB & $\%$ & -34.9 & -49.2 & -41.1 & -39 & -9.8 & -17.0 & -17.2 & -2 & -24.4 & -36.8 & -30.5 & -26.0 \\
\hline $\mathrm{ME}$ & $\mu \mathrm{g} \mathrm{m}^{-3}$ & 7.0 & 8.2 & 7.3 & 7.2 & 8.0 & 7.5 & 7.7 & 6.4 & 10.4 & 10.3 & 10.6 & 9.9 \\
\hline FE & $\%$ & 38.6 & 49.2 & 41.3 & 41.9 & 44.5 & 41.5 & 42.7 & 38.1 & 64.3 & 66.4 & 66.2 & 62.3 \\
\hline RMSE & $\mu \mathrm{g} \mathrm{m}^{-3}$ & 9.5 & 10.2 & 9.6 & 8.9 & 11.7 & 11.0 & 10.9 & 8.2 & 14.8 & 14.5 & 15.1 & 13.9 \\
\hline $\mathrm{r}$ & - & 0.40 & 0.70 & 0.60 & 0. & 0.66 & 0.78 & 0.77 & 0.78 & 0.20 & 0.33 & 0.22 & 0.37 \\
\hline IA & - & 0.45 & 0.48 & & & 0.39 & & 0.58 & 0.81 & 0.46 & 0.50 & 0.41 & 0.57 \\
\hline FO2 & $\%$ & 88.2 & 64.7 & 76.5 & 76.5 & 88.2 & 76.5 & 76.5 & 88.2 & 54.7 & 53.1 & 53.4 & 57.2 \\
\hline
\end{tabular}

els underestimate observed values, but again the Polish system is able to capture the highest concentration that occurred on 26 December 2000. During the 'warm' season model performance is worse, especially for May to August in case of the Kuźnia site (Fig. 7a). The discrepancies between observations and predictions are most likely due to a lack of consideration of mineral as well as re-suspended dust in our modelling systems and shortcomings in the reconstruction of some aerosol process formations, especially secondary organic aerosol (SOA) formation. An underestimation in emission amounts could also be a cause of these disagreements. The underprediction of $\mathrm{PM}_{10}\left(\mathrm{PM}_{2.5}\right)$ levels in summer has also been found in long-term simulations (the entire year 2001) performed by Appel et al. (2008) for the eastern US (MM5/CMAQ). At the same time, these authors obtained overpredictions in winter. Two CTMs, CMAQ and CAMx driven by MM5, were used for a full-year simulations (2002), that were performed for the eastern USA by Tesche et al. (2006). During all seasons, the results of this study show that both models tended to overpredict $\mathrm{PM}_{10}$. However, on the other hand, a model inter-comparison study of Stern et al. (2008), which focussed on episodes with elevated $\mathrm{PM}_{10}$ in Germany, showed a clear tendency in the models toward an increasing underestimation of $\mathrm{PM}_{10}$ with increasing observed concentrations.

The poorer modelling systems skill in the simulation of particles compared to that of $\mathrm{O}_{3}$ is reported by numerous authors (e.g. Vautard et al. 2007, Honoré et al.
2008, Chemel et al. 2010, Lonati et al. 2010). This is still due to significant uncertainty in our knowledge concerning the sources and the sinks of aerosols.

The quantification metrics calculated for $\mathrm{PM}_{10}$ are given in Table 3.

For 'overlapping modelling domain', all of our systems underpredict mean annual, winter, and daily $\mathrm{PM}_{10}$ concentrations, with MBs ranging from -6.6 to $-8.2 \mu \mathrm{g} \mathrm{m}^{-3},-2.4$ to $-5.1 \mu \mathrm{g} \mathrm{m}^{-3}$, and -5.5 to $-7.1 \mu \mathrm{g}$ $\mathrm{m}^{-3}$, respectively. Moreover, other bias and error metrics are found to be the lowest for the winter period (January, November, December): NMBs of -13.7 to $-28.6 \mu \mathrm{g} \mathrm{m}^{-3}$, FBs of -2.7 to $-17.2 \%$, MEs of 6.4 to $8.0 \mu \mathrm{g} \mathrm{m}^{-3}$, FEs of 38.1 to $44.5 \%$, and RMSE of 8.2 to $11.7 \mathrm{\mu g} \mathrm{m}^{-3}$. The observed standard deviation of both winter and annual spatial average concentrations is high and equal to $12.2 \mathrm{\mu g} \mathrm{m}^{-3}$ and $13.2 \mu \mathrm{g}$ $\mathrm{m}^{-3}$, respectively. This shows a diversity of PM pollution over Europe. The skill of our models to predict this variability is different: the SKVAR ranges from 0.1 to 0.6 for winter and from 0.2 to 0.5 for annual means. The lowest values are obtained from European system, while the highest come from the Polish system. This underlines the necessity of applying 3D emission fields for simulation of $\mathrm{PM}_{10}$ in the region of concern, because it allows a better account of larger concentrations from LCPs. The correlation coefficients are generally quite high for winter (from 0.66 to 0.78 ), while they display a wide range of variation for annual means (from 0.40 to 0.72 ). The skill criteria adopted for $\mathrm{PM}_{10}$ are usually less stringent than those 
for $\mathrm{O}_{3}$ (Chemel et al. 2010). Boylan \& Russell (2006) proposed that a model performance criteria for $\mathrm{PM}_{\text {, is }}$ met when both the FB and FE are $\leq \pm 60 \%$ and $\leq+75 \%$, respectively. All our modelling systems fulfil these criteria for all analysed indices, i.e. both annual and winter means as well as daily means (see Table 3). However, the benchmark of IA $>0.6$ is evidenced only by the Polish system for annual (0.61) and winter (0.81) means. For daily means, in spite of reaching the FB/FE criteria, the performance of our models is poorer than for annual/winter means. The $\mathrm{r}$ values are furthermore rather low, and range from 0.2 for European system to 0.37 for Polish one. The IA indices are also low and do not fulfil the benchmark of 0.6. The comparison between our LS and FS modelling systems shows variable models performance depending on metrics. In case of biases, they are lower for European and Polish models (MB of around $-5.5 \mu \mathrm{g} \mathrm{m}^{-3}$, NMB of $-30 \%$ and $\mathrm{FB}$ of around $-25 \%$ ) than for Czech and Hungarian (MB from -6.2 to $-7.1 \mu \mathrm{g} \mathrm{m}^{-3}$, NMB from -34.1 to $-39.3 \%$, and FB from -30.5 to $-36.8 \%$ ). Values of the error metrics are close, with MEs of around $10 \mu \mathrm{g} \mathrm{m}^{-3}$, FEs of around 62 to $66 \%$, and RMSEs of around 14 to $15 \mu \mathrm{g} \mathrm{m}^{-3}$. The FO2 decreased from 70 to $90 \%$ for annual and winter means to about $55 \%$ for daily means. These results are consistent with the recent findings of Chemel et al. (2010), who show that daily mean $\mathrm{PM}_{10}$ levels simulated with FS CMAQ model over the UK reached

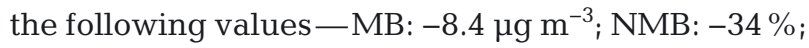
FB: $-41 \%$; ME: $13.1 \mu \mathrm{g} \mathrm{m}^{-3}$; FE: $64 \%$; RMSE: $17.6 \mu \mathrm{g}$ $\mathrm{m}^{-3}$; r: 0.47; IA: 0.87; and FO2: $26.8 \%$. Lonati et al. (2010) calculated RMSE and $r$ in reference to daily means for individual sites in the Po Valley. These authors got the RMSE of $13.0 \mathrm{\mu g} \mathrm{m}^{-3}$ for a regional background site and from 22.7 to $27.9 \mu \mathrm{g} \mathrm{m}^{-3}$ for suburban sites, while $\mathrm{r}$ amounted to 0.4 for a regional site and from 0.37 to 0.64 for suburban ones.

In general, the skill of our modelling systems to predict $\mathrm{PM}_{10}$ corresponds to the state of the art, with the Polish system showing superiority to the others. As both RCM (RegCM3) as well as CTM (CAMx) models used over Polish domain are the same as in Hungarian and Czech systems, the possible reasons for this difference is - as for $\mathrm{O}_{3}$-connected with horizontal resolution, domain size, and emission data. Our results suggest that development of detailed emission databases as well as a decrease in domain size improve the $\mathrm{PM}_{10}$ results. Indeed, the results show that national emission inventory as well as PiG mechanism applied for LCPs in the Polish domain (for primary PM and for the precursors of secondary aerosols) significantly improve the model performance. Yet, as summarized in EMEP (2007), all models currently underestimate the total $\mathrm{PM}_{10}$ and $\mathrm{PM}_{2.5}$, and thus do not achieve mass closure. Similar conclusions were drawn from the CityDelta and EuroDelta experiments for Europe (Vautard et al. 2007, Stern et al. 2008).

Summing up the above discussion, our FS models show their abilities to simulate $\mathrm{O}_{3}$ and $\mathrm{PM}_{10}$ with the level of performance which is obtained by similar modelling systems, i.e. very good for $\mathrm{O}_{3}$ and moderate for $\mathrm{PM}_{10}$. This justifies their use for future projections.

\subsection{Evaluation of RegCM3/CAMx performance for the present decade}

Since our modelling systems are intended to enable studies of the effects of changes in climate on regional $\mathrm{AQ}$, the re-analysis and GCM-driven (control) simulations for present decade should be compared to complete the evaluation study. Such evaluation was performed by Katragkou et al. (2010) and, more recently, by Zanis et al. (2011). These studies compared near-surface $\mathrm{O}_{3}$ levels simulated over Europe with RegCM3/CAMx for 1991 to 2000, driven by ERA and GCM ECHAM5 meteorology. Katragkou et al. (2010) showed that the differences between GCM- and ERA-simulated $\mathrm{O}_{3}$ fields range between \pm 4 ppbv for winter and summer as a result of the different meteorological forcing. It was also found that the area with the greatest sensitivity to the different meteorological forcing is central and southern Europe during winter and central north continental Europe during summer. Zanis et al. (2011) evaluated simulated decadal $\mathrm{O}_{3}$ levels against measurements from 68 sites of EMEP.

As it is evident from summary statistics of Table 4, the ERA predictions are closer to observations than

Table 4. Summary statistics for monthly $\mathrm{O}_{3}$ concentrations from Global Climate Model and re-analysis of European Centre for Medium-Range Weather Forecasts ERA-40 field (ERA) runs, over the period 1991-2000, considering all predicted/observed pairs of values from the 68 European Monitoring and Evaluation Program sites within European large scale (LS) domain. Statistical metrics are defined in Appendix A

\begin{tabular}{|lcrrrrrr|}
\hline \multirow{2}{*}{$\begin{array}{l}\text { Statistical } \\
\text { metrics }\end{array}$} & \multirow{2}{*}{ Unit } & \multicolumn{2}{c}{ 1st quartile } & \multicolumn{2}{c|}{ Median } & \multicolumn{2}{c|}{ 3rd quartile } \\
& & ERA & GCM & ERA & GCM & ERA & GCM \\
\hline r & - & 0.60 & 0.50 & 0.80 & 0.72 & 0.85 & 0.79 \\
FB & $\%$ & -6.70 & 4.95 & 3.95 & 15.50 & 14.23 & 30.18 \\
SKVAR & - & 0.95 & 0.82 & 1.08 & 0.94 & 1.25 & 1.06 \\
\hline
\end{tabular}


the GCM predictions, because their meteorology follows the synoptic scale variability in a more realistic way than GCM meteorology. The correlation between predicted and observed monthly $\mathrm{O}_{3}$ values ranges between 0.7 and 0.9 for the majority of sites in the ERA results and is bigger than 0.6 in the GCM ones. This indicates that the monthly variability of predicted $\mathrm{O}_{3}$ is in phase with the observed one in most cases. The FB values show a tendency towards model overestimation, as the median FB from 68 sites is $+3.9 \%$ for the ERA run and $+15.5 \%$ for the GCM run, indicating a shift to more frequently overestimated $\mathrm{O}_{3}$ values in GCM outputs. Concerning the amplitude of $\mathrm{O}_{3}$ variance, a satisfactory agreement with observations is found for the majority of sites. For $50 \%$ of the sites, the SKVAR values range between 0.95 (1st quartile) and 1.25 (3rd quartile) in ERA and between 0.82 (1st quartile) and 1.06 (3rd quartile) in GCM results, indicating a slight shift to more frequently underestimated amplitudes of $\mathrm{O}_{3}$ variance in the CR. Overall, despite the presence of some systematic biases, this evaluation indicates a relatively good performance of our basic modelling system, and thus justifies our overall assessment that it is suitable for present and future regional climate-AQ simulations.

\subsection{Effects of climate change on future air quality}

\subsubsection{Ozone}

The European future RegCM3/CAMx simulations show that changes in summer near-surface $\mathrm{O}_{3}$ mainly occur for the end of the 21st century, ranging from -2 to $+1 \mathrm{ppbv}$ for NF (2041-2050) and from +1 to +5 ppbv for FF (2091-2100) decades (Fig. 8).

Fig. 8a shows the summer $\mathrm{O}_{3}$ over Europe as calculated by GCM-driven system for the control

Fig. 8. Spatial distribution of summer mean $\mathrm{O}_{3}$ concentrations (ppbv), calculated by European large scale modelling system, for (a) present (control) decade 1991-2000, and climate change impacts on summer mean $\mathrm{O}_{3}$ in terms of the differences (ppbv) between (b) near future 2041-2050 or (c) far future 2091-2100 and control decade. The statistically insignificant differences, as determined by Student's $t$-test (at $95 \%$ significance level), are masked

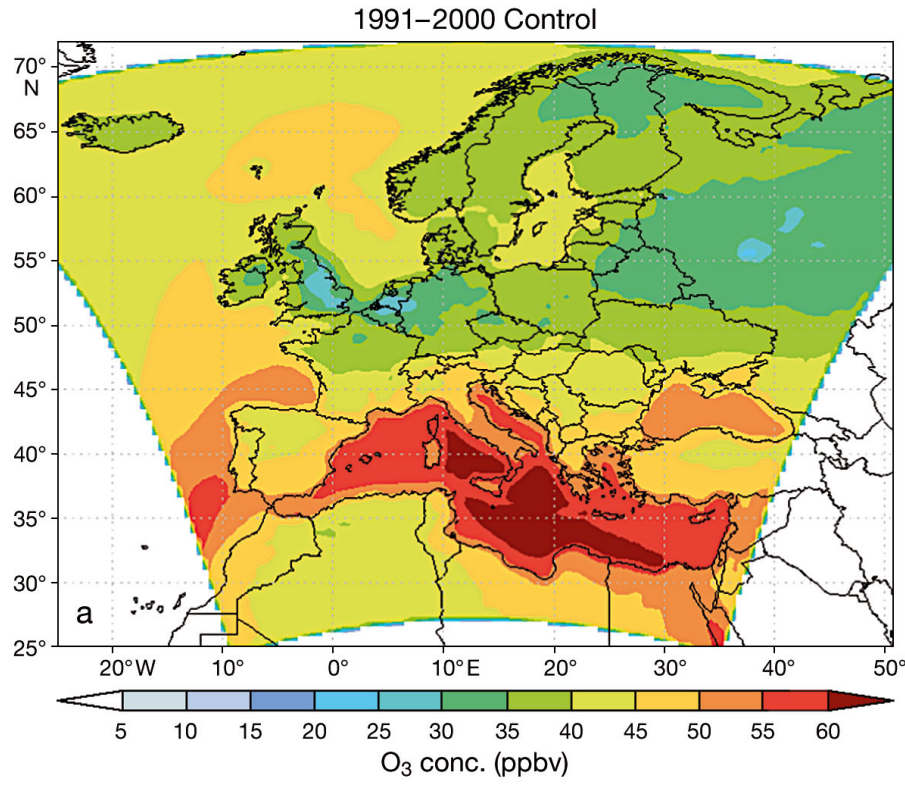

(2041_2050) - (1991_2000)
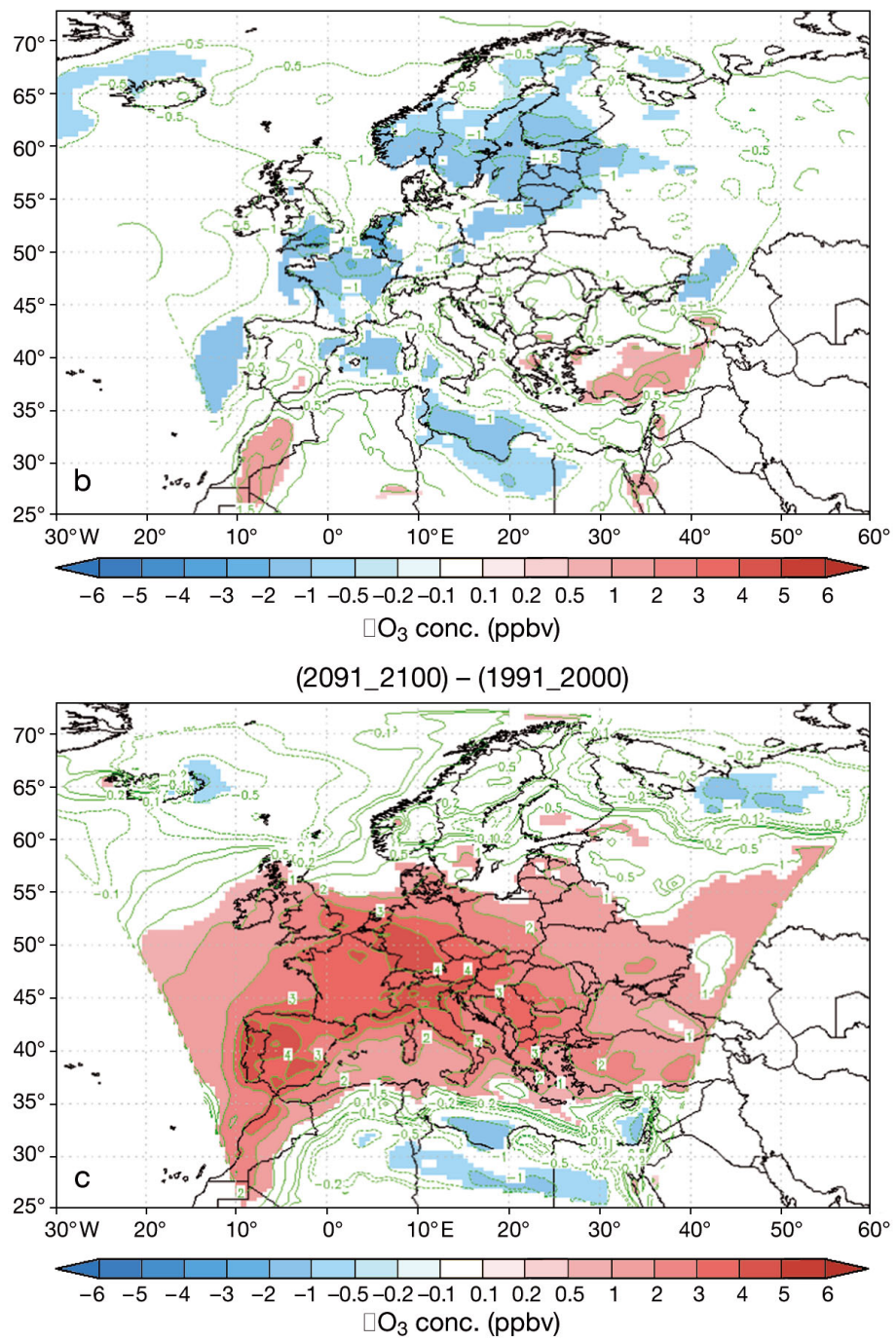

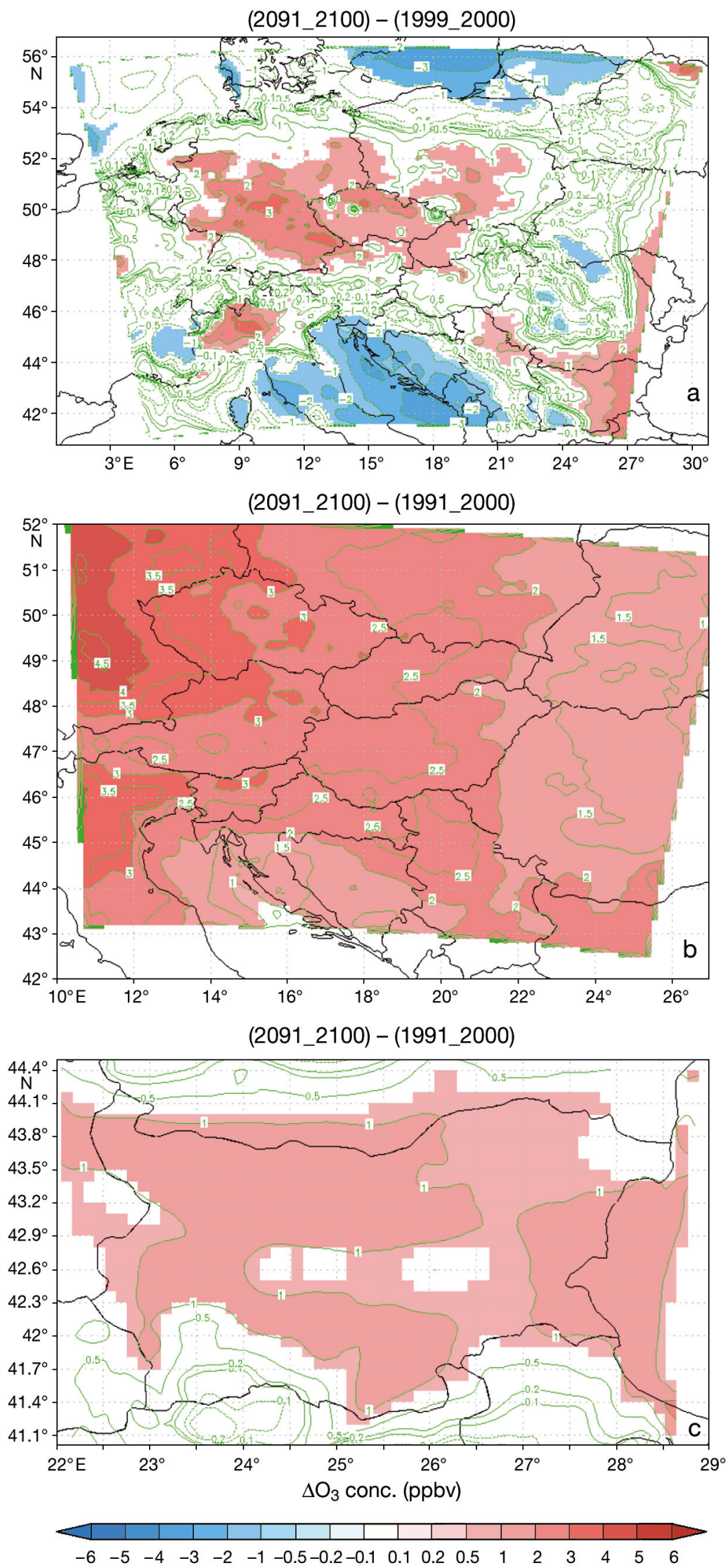

period 1991-2000 (CR). The levels of $\mathrm{O}_{3}$ are lower over the continent than over the sea due to lower $\mathrm{O}_{3}$ dry deposition over water versus land surfaces, where significant uptake of $\mathrm{O}_{3}$ by vegetation takes place. In addition, due to more intense photochemistry in southern latitudes there is a positive gradient in $\mathrm{O}_{3}$ from north to south, with the higher $\mathrm{O}_{3}$ levels over the Mediterranean basin. Fig. 8b shows the spatial distribution of differences $(\Delta)$ in summer $\mathrm{O}_{3}$ between NF and CR over Europe, and reveals statistically insignificant changes for the majority of the domain, with small decreases from -1 to $-2 \mathrm{ppbv}$ in northern Europe and slight increases (up to +1 ppbv) over the Balkan region and the area around Gibraltar. The statistical significance of obtained $\Delta$ was determined by Student's $t$-test, for $95 \%$ significance level. Fig. 8c illustrates the respective changes between $\mathrm{FF}$ and $\mathrm{CR}$, that show increases in summer $\mathrm{O}_{3}$ (at different magnitudes) over almost all Europe. The changes of $\mathrm{O}_{3}$ get as large as 5 ppbv over western continental Europe, while for the rest of the domain, $\mathrm{O}_{3}$ increases by about 2-4 ppbv. Over Scandinavia and northern Russia the changes are statistically insignificant. These findings are in line with Hedegaard et al. (2008) who-by using the CTM model DEHM driven by Atmosphere-Ocean GCM ECHAM4-OPYC3 under SRES A2 scenario - found an increase in $\mathrm{O}_{3}$ over the northern hemisphere in the FF climate (2090-2099) as compared to present decade (1990-1999). For Europe, this increase in $\mathrm{O}_{3}$ amounts to about $12 \%$ of present decade levels. Our results correspond also to Meleux et al. (2007)'s findings for Europe. These authors applied the CHIMERE model driven by RegCM forced by HadAM3H GCM under A2/B2 SRES scenarios and obtained the maximum increase in summer mean $\mathrm{O}_{3}$ over eastern France and western Germany, which ranges from 7 to 10 ppbv.

The future $\mathrm{O}_{3}$ projections modelled by our FS systems are analysed solely for $\Delta$ between FF and CR (Fig. 9). All models show that sum-

Fig. 9. Effects of climate change on summer mean $\mathrm{O}_{3}$ concentrations in terms of the differences (ppbv) between far future 2091-2100 and present (control) 1991-2000 decades, simulated by: (a) Czech, (b) Hungarian, and (c) Bulgarian fine scale modelling systems. The statistically insignificant differences, as determined by Student's $t$-test (at $95 \%$ significance level), are masked 
mer $\mathrm{O}_{3}$ increases in FF with the spatial distribution that is close to the one obtained from LS simulations but with a lower magnitude (from +1 to +4 ppbv). For the Hungarian and Bulgarian domains almost all $\mathrm{O}_{3}$ increases are statistically significant (Fig. 9b,c), while $\Delta$ obtained from the Czech system (Fig. 9a) are significant only for central part of the domain, with increases that range: from 1 to $2 \mathrm{ppbv}$ in central and southern Poland, central-eastern Germany, the majority of the Czech Republic and western Slovakia; up to $3 \mathrm{ppbv}$ in the northern Czech Republic and southern Germany; and up to 4 ppbv over central and southern Germany and the northern Czech Republic. The increase of $\mathrm{O}_{3}$ modelled by the Hungarian system shows a longitudinal distribution, and amounts to 1-2 ppbv, up to $3 \mathrm{ppbv}$ and up to $4 \mathrm{ppbv}$ for the eastern, central and western parts of the domain, respectively. The lower increases of $\mathrm{O}_{3}$ obtained from the FS models (as compared to those from the LS model), are in agreement with previous studies showing that higher resolution models tend to produce less $\mathrm{O}_{3}$ from the same levels of precursor emissions because of a lower rate of mixing generated when emissions are added to smaller grid boxes (Stevenson et al. 2006).

The general increase in $\mathrm{O}_{3}$ we found might be due to a multiplicity of climate factors, such as increased temperature, decreased wet removal related to decrease of summer precipitation, increased photolysis of primary and secondary pollutants, and increased biogenic emissions due to higher temperatures (Meleux et al. 2007). We analysed the contribution of different factors by comparing their changes (calculated by FS RegCM3) with the changes in summer $\mathrm{O}_{3}$. The spatial patterns of $\Delta$ in summer surface temperature $(\mathrm{T})$, precipitation rate $(\mathrm{PR})$ and the PBL height $\left(\mathrm{H}_{\mathrm{PBL}}\right)$ between FF and CR are presented in Fig. 10.

The simulated changes of $2 \mathrm{~m} \mathrm{~T}$ in FF summer are clearly seen for all CEE domains (Fig. 10a). The increase in $\mathrm{T}$ has a latitudinal distribution, ranging from $2^{\circ}$ to $2.5^{\circ} \mathrm{C}$ in northern Poland and

Fig. 10. Summer (June, July, August) differences in (a) average $2 \mathrm{~m}$ temperature, (b) precipitation, and (c) planetary boundary layer (PBL) height between far future 2091-2100 and present (control) 1991-2000 decades, simulated with fine-scale RegCM3-Beta over the Czech domain
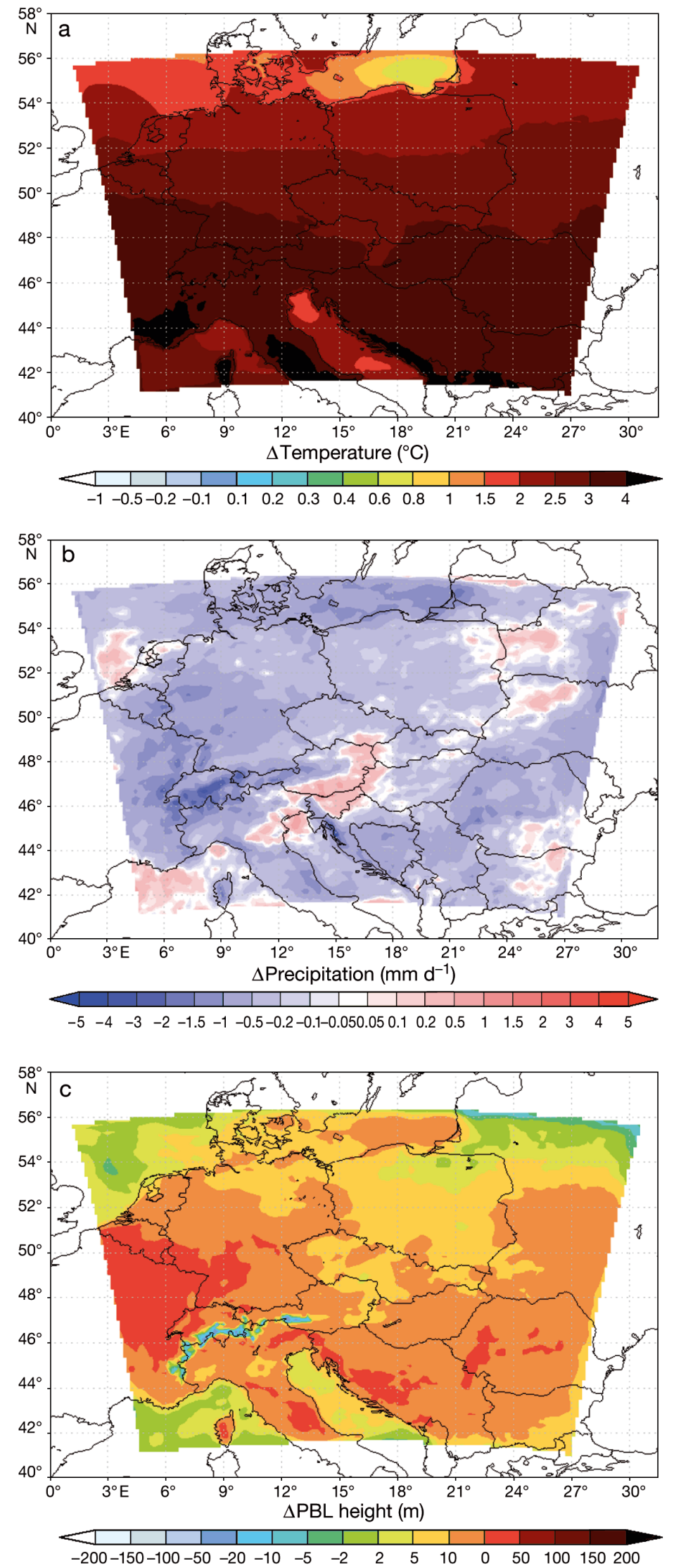

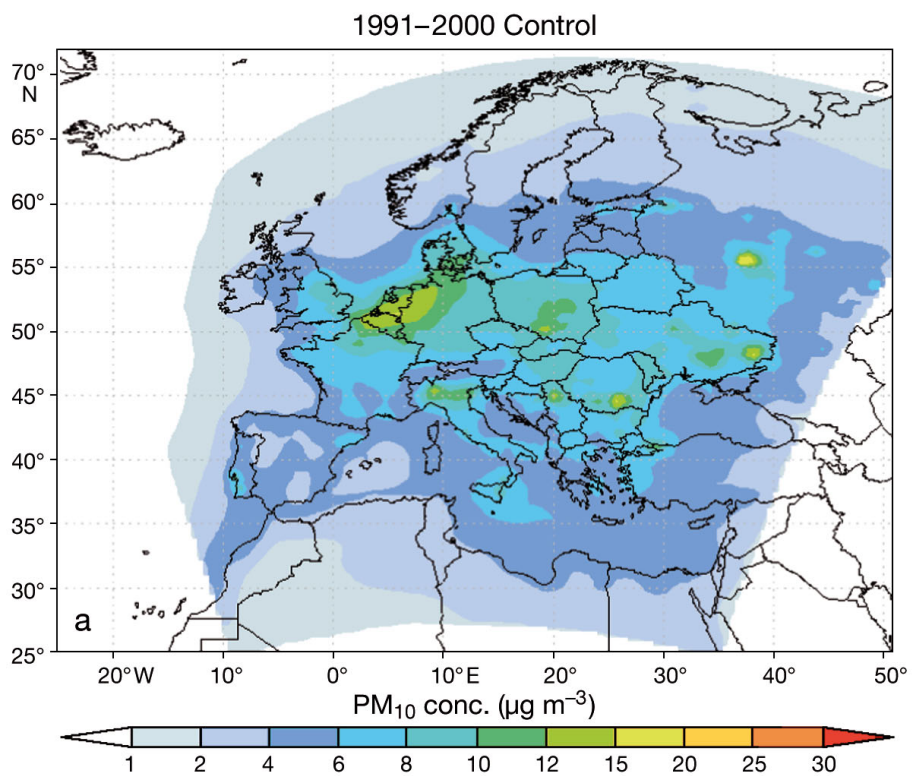

(2041_2050) - (1991_2000)

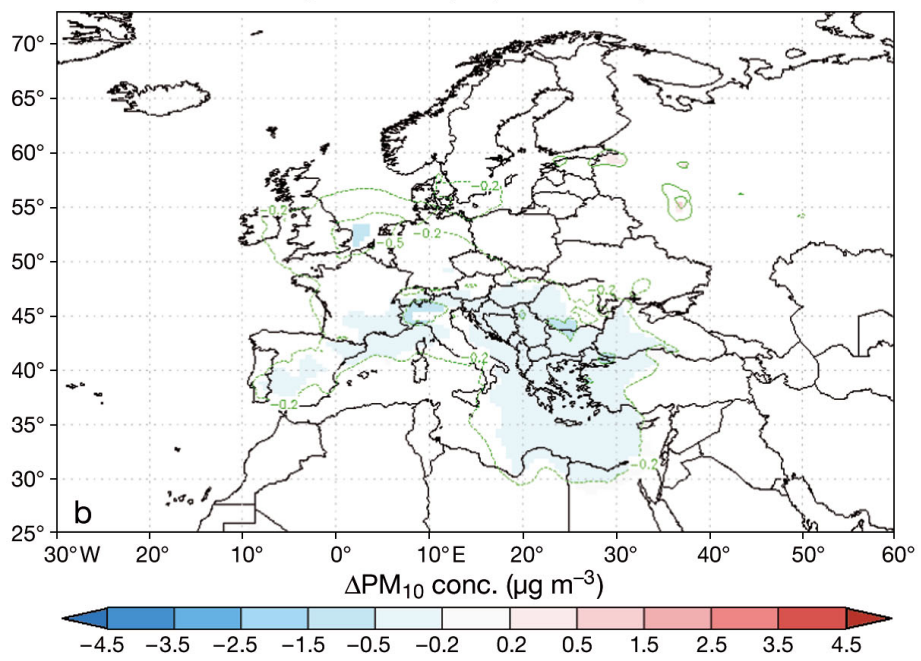

(2091_2100) - (1991_2000)

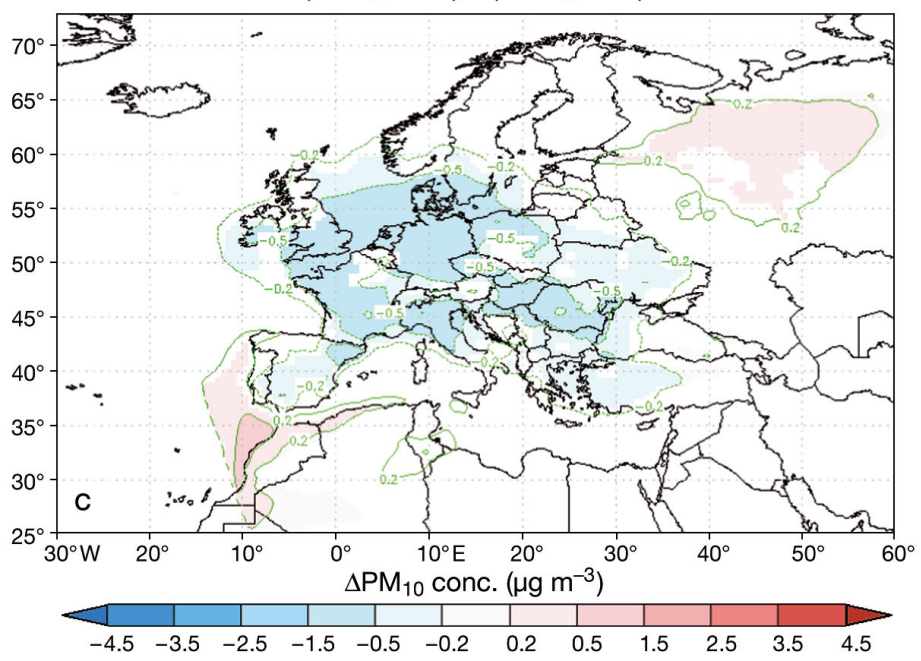

Germany, up to $3^{\circ} \mathrm{C}$ in southern Poland, Germany, Czech Republic, Slovakia and northern Austria, and up to $4^{\circ} \mathrm{C}$ over central and southern Austria and Hungary. This $\Delta(\mathrm{T})$ pattern is consistent with the positive summer $\Delta\left(\mathrm{O}_{3}\right)$ displayed in Fig. 9a. Previous studies have shown that increase of $\mathrm{T}$ in future climate might influence $\mathrm{O}_{3}$ levels in many ways, such as by enhancing biogenic hydrocarbon emissions, decomposition of PAN at higher $\mathrm{T}$, and the increase of $\mathrm{O}_{3}$ production by a rise in water vapour content at high $\mathrm{NO}_{\mathrm{x}}$ levels (Liao et al. 2006). Moreover, the modelled decrease in future summer $\mathrm{PR}$, with $\Delta(\mathrm{PR})$ from -1 to $-1.5 \mathrm{~mm} \mathrm{~d}^{-1}$ for the majority of the domain and up to $-2 \mathrm{~mm} \mathrm{~d}^{-1}$ over the Alps (Fig. 10b) is also in line with projected $\mathrm{O}_{3}$ increase. On the other hand, the increase of the $\mathrm{H}_{\mathrm{PBL}}$ that RegCM3 shows for FF summer (Fig. 10c) could counterbalance the increase of summer $\mathrm{O}_{3}$ induced by $\mathrm{T}$ and $\mathrm{PR}$. However, this projected increase of $\mathrm{H}_{\mathrm{PBL}}$ appears to be very low (up to $20 \mathrm{~m}$ for the majority of domain); thus it is very likely that the influence of this factor is minor.

\subsubsection{Particulate matter}

The European future projections for NF show that changes in annual mean $\mathrm{PM}_{10}$ levels are statistically insignificant for the majority of CEE (with the exception of Hungary and western Austria where $\Delta\left(\mathrm{PM}_{10}\right)$ is negative and extends up to

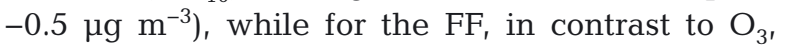
$\mathrm{PM}_{10}$ is projected to decrease for almost all Europe, by up to $-1.5 \mu \mathrm{g} \mathrm{m}^{-3}$ (Fig. 11).

The annual mean $\mathrm{PM}_{10}$ distribution over Europe for the control period is shown in Fig.11a. In general, calculated concentrations vary from 4 to $20 \mu \mathrm{g}$ $\mathrm{m}^{-3}$, with the highest levels found in Benelux countries, western Germany, northern Italy, northern Serbia, southern Poland, southern Romania, eastern and western Ukraine, and in Russia (surroundings of Moscow). Most of these 'hot spots' of high $\mathrm{PM}_{10}$ are caused by local emission sources such as LCPs (mainly coal-fired electric power stations in CEE) and dense traffic (especially in highly popu-

Fig. 11. Spatial distribution of annual mean $\mathrm{PM}_{10}$ concentrations, calculated by European large scale modelling system, for (a) present (control) decade 1991-2000 and climate change impacts on annual mean $\mathrm{PM}_{10}$ levels in terms of the differences between (b) near future 20412050, or (c) far future 2091-2100 and control decade. Statistically insignificant differences, as determined by Student's $t$-test (at 95\% significance level), are masked 
lated Benelux countries). Additionally, a wellknown PM 'hot spot' in the Po Valley is due to very unfavourable meteorological conditions.

For the majority of the European 'hot spots' described above, our LS model shows statistically insignificant changes in NF (Fig. 11b), while in FF (Fig.11c) the decrease in $\mathrm{PM}_{10}$ within the range of -0.5 to $-1.5 \mu \mathrm{g} \mathrm{m}^{-3}$ is projected for the majority of central Europe, including areas from southern England to northern Italy, Romania, and Poland. At the same time, statistically insignificant changes in FF are modelled for Baltic eastern countries, Scandinavia, and Russia. The positive $\Delta\left(\mathrm{PM}_{10}\right)$ is projected only for the Portuguese Atlantic coast as well as centralnorthern Russia, including a Moscow 'hot spot' (small increase up to $0.5 \mu \mathrm{g} \mathrm{m}^{-3}$ ). However, for the main 'hot spot' of CEE, i.e. for southern Poland, FF projections of our LS model remain statistically insignificant, as well as for the major parts of Czech Republic and Austria.

Similarly to $\mathrm{O}_{3}$, we analysed $\mathrm{PM}_{10}$ projections from our FS models only by studying $\Delta$ between FF and the CR (Fig. 12). Almost all results obtained by Czech model are statistically significant and show negative $\Delta\left(\mathrm{PM}_{10}\right)$ for the whole domain (Fig. 12a). The biggest $\mathrm{PM}_{10}$ decrease is obtained for the northernwestern part of the domain, i.e. for Benelux countries (up to $-3.5 \mu \mathrm{g}$ $\left.\mathrm{m}^{-3}\right)$. The projected negative $\Delta\left(\mathrm{PM}_{10}\right)$ shows an increasing trend from north to south. For Germany and northern Poland, $\Delta\left(\mathrm{PM}_{10}\right)$ rises up to $-1.5 \mu \mathrm{g} \mathrm{m}^{-3}$ and up to $-0.5 \mu \mathrm{g} \mathrm{m}^{-3}$ for the rest of domain. However, for the 'hot spots' in Po Valley and in southern Romania, a greater $\mathrm{PM}_{10}$ decrease of $-2.5 \mathrm{\mu g} \mathrm{m}^{-3}$ is projected, whereas for Czech Republic, Austria and northern Poland $\Delta\left(\mathrm{PM}_{10}\right)$ is up to $-1.5 \mu \mathrm{g} \mathrm{m}^{-3}$. For the majority of the eastern part of the Polish domain (Fig. 12b), including eastern Germany, western and southern Czech Republic as well as western and southern Poland, $\Delta\left(\mathrm{PM}_{10}\right)$ does not reach statistical significance. For eastern Poland, $\Delta\left(\mathrm{PM}_{10}\right)$ is within the range of $-0.5 \mu \mathrm{g} \mathrm{m}^{-3}$ to $-2.5 \mu \mathrm{g} \mathrm{m}^{-3}$, which corresponds to about $10 \%$ of the maximal values calculated for control decade (see Fig. 11a).

Fig. 12. Climate change impacts on annual mean $\mathrm{PM}_{10}$ concentrations in terms of the differences $\left(\mu \mathrm{g} \mathrm{m}^{-3}\right)$ between far future 2091-2100 and present (control) 1991-2000 decades, simulated by: (a) Czech, (b) Polish, and (c) Hungarian fine scale modelling systems. Statistically insignificant differences, as determined by Student's $t$-test (at $95 \%$ significance level), are masked
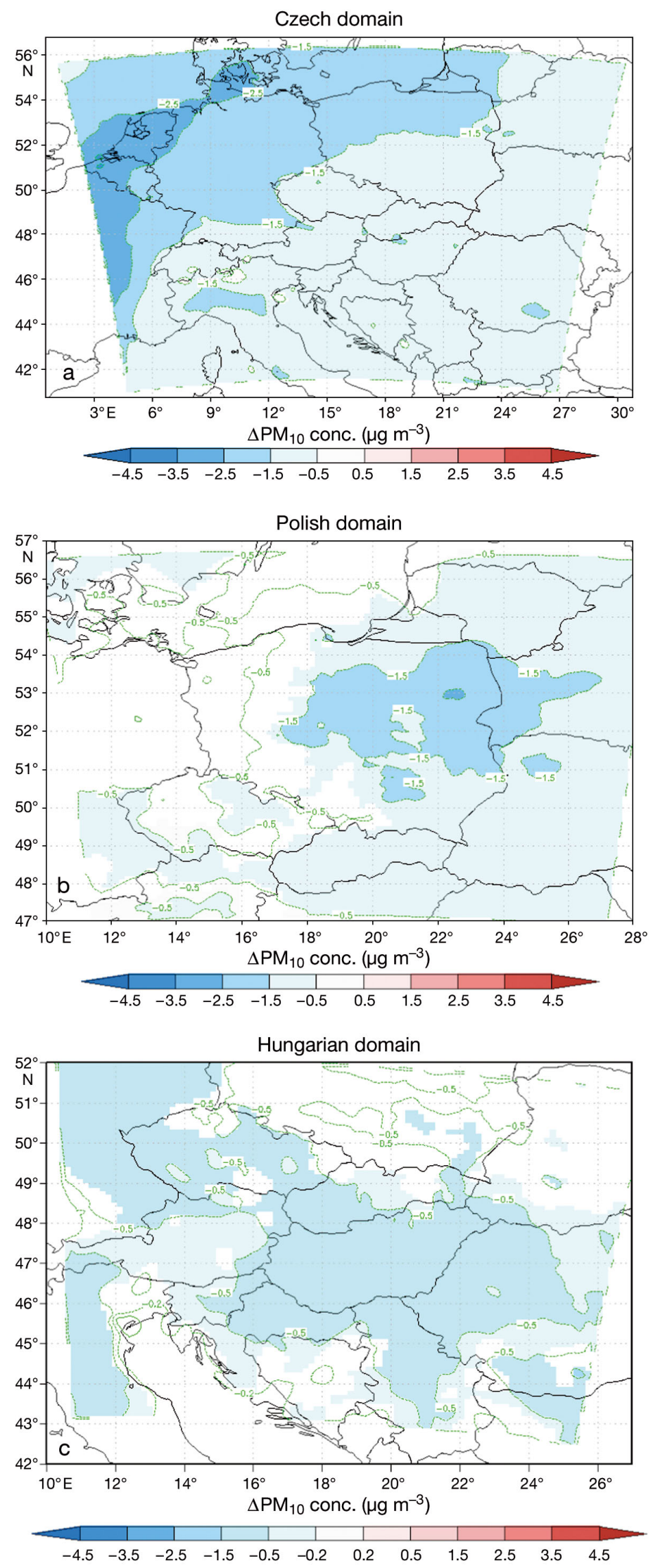

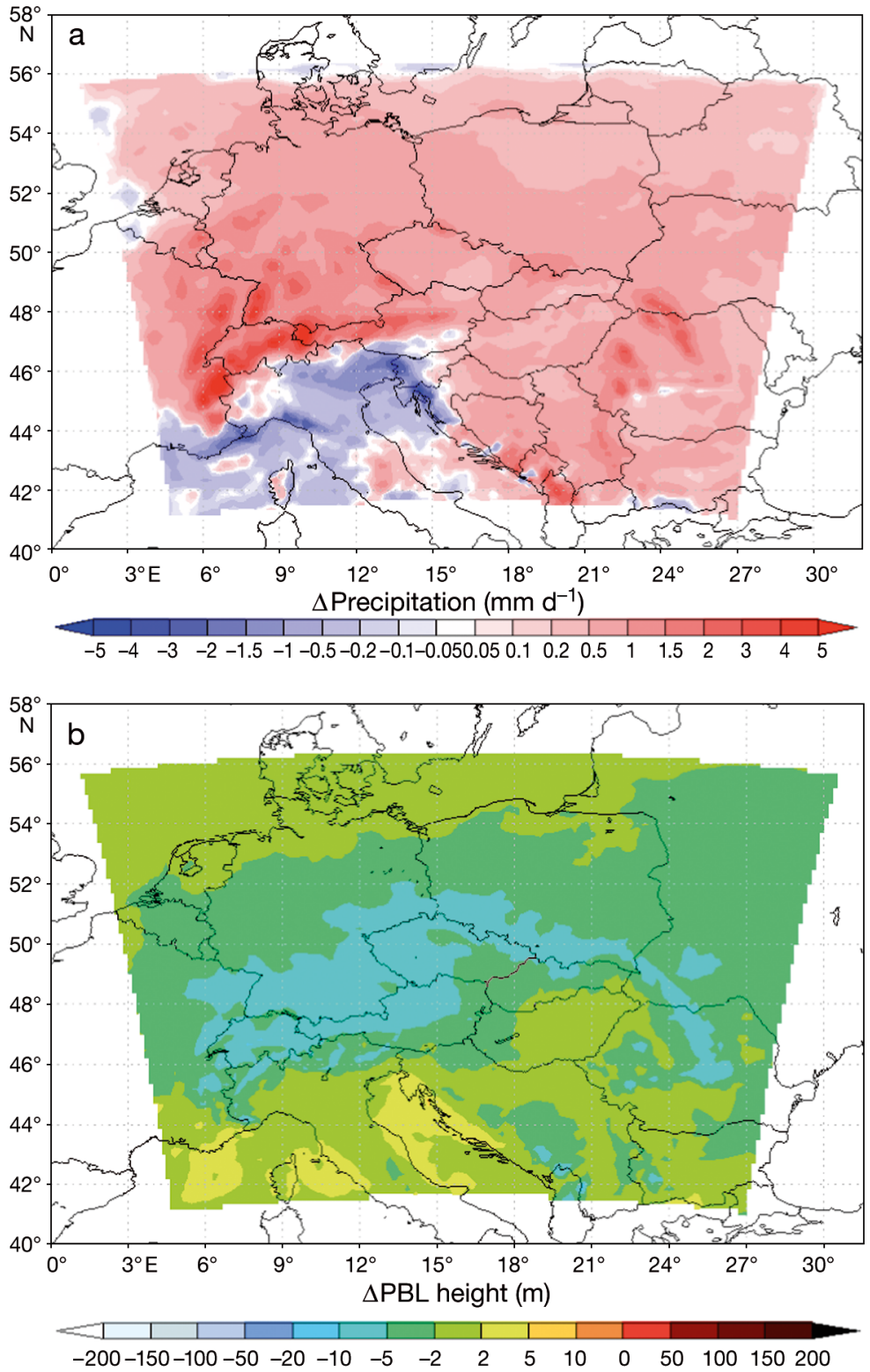

Fig. 13. Winter (January, November, December) differences in (a) precipitation $\left(\mathrm{mm} \mathrm{d}^{-1}\right)$ and (b) planetary boundary layer (PBL) height $(\mathrm{m})$ between far future 2091-2100 and present (control) 1991-2000 decades, simulated with fine-scale RegCM3-Beta over Czech domain

For both northern and southern parts of the Hungarian domain (Fig. 12c), $\Delta\left(\mathrm{PM}_{10}\right)$ values are found to be statistically insignificant, mainly in southern Poland, western Ukraine and the Adriatic sea. For Hungary, western Slovakia and a major part of the Czech Republic, $\Delta\left(\mathrm{PM}_{10}\right)$ extends from -0.5 to $-1.5 \mu \mathrm{g} \mathrm{m}{ }^{-3}$, while for Austria the decrease is smaller $(-0.2$ to $-0.5 \mu \mathrm{g} \mathrm{m}^{-3}$ ).

The fact that observed correlations of $\mathrm{PM}_{10}$ levels with meteorological variables are found to be weaker than for $\mathrm{O}_{3}$ reflects the diversity of PM components as well as the complexity of the processes which they undergo. Climate change might influence PM levels by modifying wet deposition, climate-sensitive precursor emissions, aerosol thermodynamic equilibrium, and boundary layer characteristics. The majority of previous studies reported a decrease in $\mathrm{PM}_{10}$ (up to $-1 \mathrm{\mu g} \mathrm{m}^{-3}$ ) as a consequence of the projected increase in precipitation and thus an increase in PM sinks due to wet deposition (Racherla \& Adams 2006, Tagaris et al. 2007). Moreover, Liao et al. (2006) drew attention to the effect of higher water vapour in the future climate, which leads to an increased production of sulphate aerosols through higher $\mathrm{H}_{2} \mathrm{O}_{2}$ concentrations, causing faster $\mathrm{SO}_{2}$ oxidation. More rapid $\mathrm{SO}_{2}$ oxidation is also caused directly by a temperature increase. On the other hand, nitrate and organic semi-volatile components included in PM decrease as they shift from the particle to the gas phase with increasing temperature (Dawson et al. 2007). Furthermore, temperature is shown to be positively correlated with biogenic hydrocarbon emission, which in turn are precursors of SOAs.

The main difficulty of projecting future PM levels is that the effects of climate change on PM depend on the composition of the particles. In our study, however, as we deal only with $\mathrm{PM}_{10}$ mass concentration, the lack of knowledge about species associated with PM limits the interpretation. Therefore, our analysis is focussed on those climatic factors that are known to have effects on all PM species, i.e. $\mathrm{PR}$ and $\mathrm{H}_{\mathrm{PBL}}$. As was demonstrated in Fig. 7, the annual mean $\mathrm{PM}_{10}$ in the study region are dominated by high levels in winter, thus we further analyse winter climatic factors below.

Fig. 13 displays the spatial patterns of projected $\Delta$ between FF and CR in both winter $\mathrm{PR}$ and $\mathrm{H}_{\mathrm{PBL}}$. The increase in winter $\mathrm{PR}$ in $\mathrm{FF}$ decade is clearly seen for the CEE domain (Fig. 13a), amounting to 0.2 to $0.5 \mathrm{~mm} \mathrm{~d}^{-1}$ in northern Poland, southern Czech Republic, southern Slovakia and northern Hungary, while rising up to $1 \mathrm{~mm} \mathrm{~d}^{-1}$ in western and southern Poland, northern Germany, southern Hungary and the majority of the Czech Republic, and up to $4 \mathrm{~mm} \mathrm{~d}^{-1}$ over central and northern Austria and in mountainous areas. Only in the southern part of Austria is a decrease in PR of 
up to $2 \mathrm{~mm} \mathrm{~d}^{-1}$ projected. Note that this pattern of future changes in PR is concomitant with the projected $\mathrm{PM}_{10}$ decreases. In contrast, when the low negative pattern of future change in $\mathrm{H}_{\mathrm{PBL}}$ is projected (Fig. 13b), small values of $\Delta\left(\mathrm{H}_{\mathrm{PBL}}\right)$ of -2 to $+2 \mathrm{~m}$ are found for northern Poland and Germany as well as central-eastern Hungary, up to $-5 \mathrm{~m}$ over Slovakia, central Poland, central Germany, western Austria and eastern Hungary, and up to $-10 \mathrm{~m}$ in southern Poland, southern Germany, and central and western Austria. Results of Dawson et al. (2007), who studied the sensitivity of $\mathrm{PM}_{2.5}$ to climate in the Eastern US, showed that the impact of mixing height on different $\mathrm{PM}_{2.5}$ species was proportional to their relative concentrations, indicating that the mixing height represents a simple dilution effect that does not induce major chemical feedbacks. Thus, the decrease in height of the mixing layer should, in general, lead to an increase in concentrations of PM. Moreover, in the abovementioned study, the fact that the authors were able to show a decrease in the average land cell $\mathrm{PM}_{2.5}$ concentration by $-1.3 \%(100 \mathrm{~m})^{-1}$ for January (Dawson et al. 2007) strongly indicates that mixing height has a minor influence on $\mathrm{PM}_{10}$ levels projected by our models.

\section{SUMMARY AND CONCLUSIONS}

In this study, we focused on the modelling of anticipated impacts of climate changes on AQ in the targeted regions of CEE. We established and compared 4 domains (Polish, Czech, Hungarian, and Bulgarian) in CEE - a region which is characterized by complex terrain, and by significant air pollution, mainly due to high levels of coal burning. The climate change-AQ studies dedicated to this region have been scarce so far. For assessment of the robustness of our models, we propose a comprehensive 'operational' methodology for evaluation of model performance. A clear overall conclusion from this evaluation exercise is that both LS and FS RCM/CTM modelling systems used in our study are skillful for the simulation of $\mathrm{O}_{3}$. Although all models overestimate low (mainly night-time) $\mathrm{O}_{3}$ levels and underestimate daily peak values, their evaluation fulfil the criteria for a very good model performance, set by Morris et al. (2005b). The improvement in model skill was obtained for small size (national) domains; however the expected improvement due to higher resolution, was not found in the case of $\mathrm{O}_{3}$. Concerning $\mathrm{PM}_{10}$, the performance of our models was moderate, with significant underprediction of observed values and a better performance for winter than for summer, yet the skill criteria for PM of Boylan \& Russell (2006) are met as well. In addition to the lack of maturity of PM modelling by CTMs, the underestimation is most likely due to the fact that among the physical and chemical processes that particulates undergo in the atmosphere, there are several processes which are poorly understood. Also, some important emission processes, such as grass burning, forest fires, as well as windblown and re-suspended dust have not been included in the models. Nevertheless, we could reach an improvement in performance by applying both a higher resolution and a smaller domain size in the case of $\mathrm{PM}_{10}$. This improvement is mainly due to a detailed emission inventory and the use of the PiG algorithm of CAMx for LCPs, employed especially in Polish modelling system. Moreover, our results show that the modelling systems we established for small national domains appear to be comprehensive and robust tools for a variety of applications, such as climate-AQ regional simulations.

The main conclusions that can be drawn from our simulations for control and future decades are that the anticipated effects of climate change (under A1B scenario of IPCC) on $\mathrm{O}_{3}$ and $\mathrm{PM}_{10}$ levels in CEE appear to be statistically insignificant for the NF period and significant for the FF decade, with directions of change depending on the pollutant considered. In the case of summer mean $\mathrm{O}_{3}$, the modelled statistically significant changes induced solely from climate change for the FF were from +1 to +5 ppbv in European LS simulations, while up to +4.0 ppbv in the FS runs. This is in line with other studies showing that higher resolution models tend to produce less $\mathrm{O}_{3}$ (Stevenson et al. 2006). The modelled $\mathrm{O}_{3}$ increase was found to be consistent with temperature increases (from 2 to $4^{\circ} \mathrm{C}$ ) and precipitation decreases (from -1 to $-2 \mathrm{~mm} \mathrm{~d}^{-1}$ ) projected by FS RegCM3 for FF summer in the study region. In contrast, our models projected a decrease in annual mean $\mathrm{PM}_{10}$ for the majority of CEE in FF, up to $-1.5 \mu \mathrm{g} \mathrm{m}^{-3}$ in LS simulations and up to $-3.5 \mu \mathrm{g} \mathrm{m}^{-3}$ in FS ones. The modelled $\mathrm{PM}_{10}$ decrease was found to correspond with projected winter precipitation increase (from 0.2 to $4.0 \mathrm{~mm} \mathrm{~d}^{-1}$ ).

Summing up our results, it can be concluded that the increases in summer $\mathrm{O}_{3}$ modelled for the end of 21st century in CEE, calculated solely as a climate change effect, underline the importance of integrated frameworks for emission control policies that address both climate and AQ objectives. 
Acknowledgements. This work was supported by the Central and Eastern Europe Climate Change Impact and Vulnerability Assessment Project (CECILIA), financed by EU 6 . FP, Contract GOCE 037005. The calculations made at Warsaw University of Technology (WUT) were carried out at the Academic Computer Center in Gdańsk, Poland on cluster supercomputer GALERA. We wish to thank EMEP and TNO for providing anthropogenic emission data. We thank E. Coppola and F. Giorgi from ICTP, Trieste, Italy and M. Déqué from Météo-France (CNRM), Toulouse, France for providing climatic boundary conditions and for inspiring discussions. Special thanks to G. Spindler from Leibniz Institute for Tropospheric Research (IfT), Germany for providing PM data from the Melpitz research station. The authors also thank the anonymous reviewers for their helpful comments and suggestions.

\section{LITERATURE CITED}

Andreani-Aksoyoglu S, Keller J, Prévôt ASH, Baltensperger U, Flemming J (2008) Secondary aerosols in Switzerland and northern Italy: modeling and sensitivity studies for summer 2003. J Geophys Res 113:D06303. doi:10.1029/ 2007JD009053

Appel KW, Gilliland AB, Sarwar G, Gilliam RC (2007) Evaluation of the community multiscale air quality (CMAQ) model version 4.5: sensitivities impacting model performance. Ozone. Atmos Environ 41:9603-9615

Appel KW, Bhave PV, Gilliland AB, Sarwar G, Roselle SJ (2008) Evaluation of the community multiscale air quality (CMAQ) model version 4.5: sensitivities impacting model performance. Particulate matter. Atmos Environ 42: 6057-6066

Bell ML, Goldberg R, Hogrefe C, Kinney PL, and others (2007) Climate change, ambient ozone, and health in 50 US cities. Clim Change 82:61-76

> Bernard SM, Samet JM, Grambsch A, Ebi KL, Romieu I (2001) The potential impacts of climate variability and change on air pollution-related health effects in the United States. Environ Health Perspect 109:199-209

> Boylan JW, Russell AG (2006) PM and light extinction model performance metrics, goals, and criteria for three-dimensional air quality models. Atmos Environ 40:4946-4959

Builtjes PJH, van Loon M, Schaap M, Teeuwisse S and others (2003) Project on the modelling and verification of ozone reduction strategies: contribution of TNO-MEP. TNO-report MEP-R2003/166, TNO, Apeldoorn

Byun D, Schere KL (2006) Review of the governing equations, computational algorithms, and other components of the models-3 community multiscale air quality (CMAQ) modeling system. Appl Mech Rev 59:51-77

> Chang JC, Hanna SR (2004) Air quality model performance evaluation. Meteorol Atmos Phys 87:167-196

> Chemel C, Sokhi RS, Yu Y, Hayman GD, and others (2010) Evaluation of a CMAQ simulation at high resolution over the UK for the calendar year 2003. Atmos Environ 44: 2927-2939

> Dawson JP, Adams PJ, Pandis SN (2007) Sensitivity of $\mathrm{PM}_{2.5}$ to climate in the Eastern US: a modeling case study. Atmos Chem Phys 7:4295-4309

> Dennis R, Fox T, Fuentes M, Gilliland A and others (2010) A framework for evaluating regional-scale numerical photochemical modeling systems. Environ Fluid Mech (Dordr) 10:471-489
Déqué M, Piedelievre JP (1995) High-resolution climate simulation over Europe. Clim Dyn 11:321-339

Dickinson RE, Errico RM, Giorgi F, Bates G (1989) A regional climate model for the western United States. Clim Change 15:383-422

Dickinson RE, Henderson-Sellers A, Kennedy PJ (1993) Biosphere-atmosphere transfer scheme, BATS: version1E as coupled to the NCAR community climate model. NCAR Technical Note No NCAR/TN-387+STR, Boulder, CO

> Donev E, Zeller K, Avramov A (2002) Preliminary background ozone concentrations in the mountain and coastal areas of Bulgaria. Environ Pollut 117:281-286

Eder B, Yu S (2006) A performance evaluation of the 2004 release of Models-3 CMAQ. Atmos Environ 40:4811-4824

EEA (2010) The European environment—state and outlook 2010: synthesis. European Environment Agency, Copenhagen

EMEP (2007) EMEP particulate matter assessment report. EMEP/CCC-Report 8/2007. EMEP, Oslo

ENVIRON (2006) User's guide to the comprehensive air quality model with extensions (CAMx), Version 4.40. ENVIRON International Corporation, Novato, California

> Farda A, Déqué M, Somot S, Horányi A and others (2010) Model ALADIN as regional climate model for Central and Eastern Europe. Stud Geophys Geod 54:313-332

Fountoukis C, Racherla PN, Denier van der Gon HAC, Polymeneas P and others (2011) Evaluation of a threedimensional chemical transport model (PMCAMx) in the European domain during the EUCAARI May 2008 campaign. Atmos Chem Phys Discuss 11:14183-14220

Fritsch JM, Chappell CF (1980) Numerical prediction of convectively driven mesoscale pressure systems. I. Convective parameterization. J Atmos Sci 37:1722-1733

Gery MW, Whitten GZ, Killus JP, Dodge MC (1989) A photochemical kinetics mechanism for urban and regional scale computer modelling. J Geophys Res 94:12925-12956

> Gilliam RC, Hogrefe C, Rao ST (2006) New methods for evaluating meteorological models used in air quality applications. Atmos Environ 40:5073-5086

> Giorgi F, Bates GT (1989) On the climatological skill of a regional model over complex terrain. Mon Weather Rev 117:2325-2347

> Giorgi F, Meleux F (2007) Modeling the regional effects of climate change on air quality. C R Geosci 339:721-733

Grell GA (1993) Prognostic evaluation of assumptions used by cumulus parameterizations. Mon Weather Rev 121: 764-787

Grell GA, Dudhia J, Stauer DR (1994) A description of the fifth generation Penn State/NCAR Mesoscale Model (MM5). Technical report NCAR/TN-398+STR, National Center for Atmospheric Research, Boulder CO

> Guenther AB, Zimmermann PC, Harley R, Monson RK, Fall $\mathrm{R}$ (1993) Isoprene and monoterpene emission rate variability: model evaluations and sensitivity analyses. J Geophys Res 98:12609-12617

> Guenther A, Geron C, Pierce T, Lamb B and others (2000) Natural emissions of non-methane volatile organic compounds, carbon monoxide, and oxides of nitrogen from North America. Atmos Environ 34:2205-2230

> Hauglustaine DA, Lathiere J, Szopa S, Folberth GA (2005) Future tropospheric ozone simulated with a climatechemistry biosphere model. Geophys Res Lett 32: L24807. doi:10.1029/2005GL024031

Hedegaard GB, Brandt J, Christensen JH, Frohn LM and others (2008) Impacts of climate change on air pollution 
levels in the Northern Hemisphere with special focus on Europe and the Arctic. Atmos Chem Phys 8:3337-3367

- Hoek G, Forsberg B, Borowska M, Hlawiczka S and others (1997) Wintertime PM10 and black smoke concentrations across Europe: results from the PEACE study. Atmos Environ 31:3609-3622

> Hogrefe C, Hao W, Zalewsky EE, Ku JY, and others (2011) An analysis of long-term regional-scale ozone simulations over the Northeastern United States: variability and trends. Atmos Chem Phys 11:567-582

Holloway T, Spak SN, Barker D, Bretl M, and others (2008) Change in ozone air pollution over Chicago associated with global climate change. J Geophys Res 113:D22306. doi:10.1029/2007JD009775

> Honoré C, Rouil L, Vautard R, Beekmann M, and others (2008) Predictability of European air quality: assessment of 3 years of operational forecasts and analyses by the PREV'AIR system. J Geophys Res 113:D04301. doi: 10.1029/2007JD008761

> Houyoux MR, Vukovich JM, Coats CJ Jr, Wheeler NJM, Kasibhatla P (2000) Emission inventory development and processing for the seasonal model for regional air quality. J Geophys Res 105(D7):9079-9090

Huszar P, Juda-Rezler K, Halenka T, Chervenkov H, and others (2011) Effects of climate change on ozone and particulate matter over Central and Eastern Europe. Clim Res 50(1):51-68

> Isaksen ISA, Granier C, Myhre G, Berntsen TK, and others (2009) Atmospheric composition change: climate-chemistry interactions. Atmos Environ 43:5138-5192

> Jacob DJ, Winner DA (2009) Effect of climate change on air quality. Atmos Environ 43:51-63

> Jimenez-Guerrero P, Gomez-Navarro JJ, Jerez S, LorentePlazas R, and others (2011) Isolating the effects of climate change in the variation of secondary inorganic aerosols (SIA) in Europe for the 21st century (1991-2100). Atmos Environ 45:1059-1063

> Juda K (1986) Modelling of the air pollution in the Cracow area. Atmos Environ 20:2449-2458

> Juda-Rezler K, Reizer M, Oudinet JP (2011) Determination and analysis of $\mathrm{PM}_{10}$ source apportionment during episodes of air pollution in Central Eastern European urban areas: the case of wintertime 2006. Atmos Environ 45:6557-6566

Katragkou E, Zanis P, Tegoulias I, Melas D and others (2010) Decadal regional air quality simulations over Europe in present climate: near surface ozone sensitivity to external meteorological forcing. Atmos Chem Phys 10: 11805-11821

Katragkou E, Zanis P, Kioutsioukis I, Tegoulias I, Melas D, Krüger BC, Coppola E (2011) Future climate change impacts on surface ozone from regional climate-air quality simulations over Europe. J Geophys Res 116:D22307 doi:10.1029/2011JD015899

Krüger BC, Katragkou E, Tegoulias I, Zanis P and others (2008) Regional photochemical model calculations for Europe concerning ozone levels in a changing climate. Q J Hung Meteorol Serv 112:285-300

- Liao H, Chen WT, Seinfeld JH (2006) Role of climate change in global predictions of future tropospheric ozone and aerosols. J Geophys Res 111:D12304. doi:10.1029/ 2005JD006852

Liao KJ, Tagaris E, Manomaiphiboon K, Wang C and others (2009) Quantification of the impact of climate uncertainty on regional air quality. Atmos Chem Phys 9:865-878
Lonati G, Pirovano G, Sghirlanzoni GA, Zanoni A (2010) Speciated fine particulate matter in Northern Italy: a whole year chemical and transport modelling reconstruction. Atmos Res 95:496-514

> Meleux F, Solmon F, Giorgi F (2007) Increase in summer European ozone amounts due to climate change. Atmos Environ 41:7577-7587

> Monks PS, Granier C, Fuzzi S, Stohl A and others (2009) Atmospheric composition change - global and regional air quality. Atmos Environ 43:5268-5350

Morris R, Koo B, Yarwood G (2005a) Evaluation of multisectional and two-section particulate matter photochemical grid models in the western United States. J Air Waste Manag Assoc 55:1683-1693

- Morris RE, McNally DE, Tesche TW, Tonnesen G and others (2005b) Preliminary evaluation of the community multiscale air quality model for 2002 over the southeastern United States. J Air Waste Manag Assoc 55:1694-1708

Nakicenovic N, Alcamo J, Davis G, de Vries B and others (2000) Special report on emission scenarios. Cambridge University Press, Cambridge

- Nenes A, Pandis SN, Pilinis C (1998) ISORROPIA: a new thermodynamic equilibrium model for multiphase multicomponent inorganic aerosols. Aquat Geochem 4:123-152

Nolte CG, Gilliland AB, Hogrefe C, Mickley LJ (2008) Linking global to regional models to assess future climate impacts on surface ozone levels in the United States. J Geophys Res 113:D14307. doi:10.1029/2007JD008497

Pal JS, Giorgi F, Bi X, Elguindi N and others (2007) Regional climate modeling for the developing world: the ICTP RegCM3 and RegCNET. Bull Am Meteorol Soc 88: 1395-1409

> Pastuszka JS, Rogula-Kozłowska W, Zajusz-Zubek E (2010) Characterization of PM10 and PM2.5 and associated heavy metals at the crossroads and urban background sites in Zabrze, Upper Silesia, Poland, during the smog episodes. Environ Monit Assess 168:613-627

> Pun BK, Balmori RTF, Seigneur C (2009) Modeling wintertime particulate matter formation in central California. Atmos Environ 43:402-409

Racherla PN, Adams PJ (2006) Sensitivity of global tropospheric ozone and fine particulate matter concentrations to climate change. J Geophys Res 111:D24103. doi:10. 1029/2005JD006939

Ramanathan V, Feng Y (2009) Air pollution, greenhouse gases and climate change: global and regional perspectives. Atmos Environ 43:37-50

Roeckner E, Bäuml G, Bonaventura L, Brokopf R, and others (2003) The atmospheric general circulation model ECHAM5. I. Model description. Max Planck Institute for Meteorology Report 349

> Rummukainen M (2010) State-of-the-art with regional climate models. WIREs Clim Change 1:82-96

Smyth SC, Jiang W, Roth H, Moran MD and others (2009) A comparative performance evaluation of the AURAMS and CMAQ air-quality modelling systems. Atmos Environ 43:1059-1070

Steiner AL, Tonse S, Cohen RC, Goldstein AH, Harley RA (2006) Influence of future climate and emissions on regional air quality in California. J Geophys Res 111: D18303 doi:10.1029/2005JD006935

Stern R, Builtjes P, Schaap M, Timmermans R and others (2008) A model inter-comparison study focussing on episodes with elevated PM10 concentrations. Atmos Environ 42:4567-4588 
Stevenson DS, Dentener FJ, Schultz MG, Ellingsen K and others (2006) Multimodel ensemble simulations of present-day and near-future tropospheric ozone. J Geophys Res 111:D08301. doi:10.1029/2005JD006338

Syrakov D, Prodanova M, Miloshev N, Ganev K and others (2010) Climate change impact assessment of air pollution levels in Bulgaria. In: Lirkov I, Margenov S, Wasniewski J (eds) LSSC 2009. LNCS, vol 5910, Springer, Heidelberg, p 538-545

Szopa S, Hauglustaine DA, Vautard R, Menut L (2006) Future global tropospheric ozone changes and impact on European air quality. Geophys Res Lett 33:L18805. doi:10.1029/2006GL25860

Tagaris E, Manomaiphiboon K, Liao KJ, Leung LR and others (2007) Impacts of global climate change and emissions on regional ozone and fine particulate matter concentrations over the United States. J Geophys Res 112(D14):D14312

Tesche TW, Morris R, Tonnesen G, McNally D and others (2006) CMAQ/CAMx annual 2002 performance evaluation over the eastern US. Atmos Environ 40:4906-4919

Torma C, Coppola E, Giorgi F, Bartholy J, Pongrácz R (2011) Validation of a high-resolution version of the regional climate model RegCM3 over the Carpathian basin. J Hydrometeorol 12:84-100

Trapp W, Paciorek M, Paciorek MK, Juda-Rezler K and others (2010) Modelling of PM10 and PM2.5 particulate matter air pollution in Poland. In: Pawłowski L, Dudzińska M, Pawłowski A (eds) Environmental Engineering III. CRC Press-Taylor \& Francis Group, Boca Raton, FL, p 97-104

Trickl T, Cooper O, Eisele H, James P and others (2003) Intercontinental transport and its influence on the ozone concentrations over central Europe: three case studies. J Geophys Res 108:8530

Uppala SM, Kållberg PW, Simmons AJ, Andrae U and others (2005) The ERA-40 re-analysis. Q J R Meteorol Soc 131:2961-3012

Vautard R, Builtjes PHJ, Thunis P, Cuvelier C and others
(2007) Evaluation and intercomparison of ozone and PM10 simulations by several chemistry transport models over four European cities within the CityDelta project. Atmos Environ 41:173-188

> Vestreng V, Myhre G, Fagerli H, Reis S, Tarrasón L (2007) Twenty-five years of continuous sulphur dioxide emission reduction in Europe. Atmos Chem Phys 7:3663-3681

Visschedijk AJH, van der Gon DHAC (2005) Gridded European anthropogenic emission data for $\mathrm{NOx}$, SOx, NMVOC, NH3, CO, PM10, PM2.5 and CH4 for the year 2000. TNO-report B\&O-A R 2005/106, TNO, Apeldoorn

WHO (2007) Health relevance of particulate matter from various sources. Report on a WHO Workshop Bonn, Germany, 26-27 March 2007. WHO Regional Office for Europe, Copenhagen

WHO (2008) Health risks of ozone from long-range transboundary air pollution. WHO Regional Office for Europe, Copenhagen

Willmott CJ (1982) Some comments on the evaluation of model performance. Bull Am Meteorol Soc 63:1309-1313

Winiwarter W, Zueger J (1996) Pannonisches Ozon Projekt, Teilbericht Emissionen. Endbericht. Report OEFZS-A3817, Austrian Research Center, Seibersdorf

Wu S, Mickley LJ, Leibensperger EM, Jacob DJ, Rind D, Streets DG (2008) Effects of 2000-2050 global change on ozone air quality in the United States. J Geophys Res 113:D06302. doi:10.1029/2007JD008917

> Zanis P, Katragkou E, Tegoulias I, Poupkou A and others (2011) Evaluation of near surface ozone in air quality simulations forced by a regional climate model over Europe for the period 1991-2000. Atmos Environ 45: 6489-6500

> Zeng X, Zhao M, Dickinson RE (1998) Intercomparison of bulk aerodynamic algorithms for the computation of sea surface fluxes using toga coare and tao data. J Clim 11: 2628-2644

Zlatev Z (2010) Impact of future climatic changes on high ozone levels in European suburban areas. Clim Change 101:447-483 
Appendix A: Statistical metrics

If $P_{i}$ and $O_{i}$ are the predicted and the observed concentrations, respectively, $i$ refers to a given time and/or location and $N$ is the total number of samples (by time and/or location), the statistical measures described in main article are defined as:

Mean Bias (in unit of concentration):

$$
M B=\frac{1}{N} \sum_{i=1}^{N}\left(P_{i}-O_{i}\right)
$$

Normalized Mean Bias (no unit, in \%):

$$
N M B=\frac{\sum_{i=1}^{N}\left(P_{i}-O_{i}\right)}{\sum_{i=1}^{N} O_{i}} \cdot 100
$$

Fractional Bias (no unit, range $[-200,200] \%$ ):

$$
F B=\left(\frac{1}{N} \sum_{i=1}^{N} \frac{P_{i}-O_{i}}{\left(P_{i}+O_{i}\right) / 2}\right) \cdot 100
$$

Root-Mean $\underline{\text { Square E}}$ Error (in unit of concentration):

$$
R M S E=\sqrt{\frac{1}{N} \sum_{i=1}^{N}\left(P_{i}-O_{i}\right)^{2}}
$$

Fractional Error (no unit, range [0, 200]\%):

$$
F E=\left(\frac{1}{N} \sum_{i=1}^{N} \frac{\left|P_{i}-O_{i}\right|}{\left(P_{i}+O_{i}\right) / 2}\right) \cdot 100
$$

Correlation coefficient, $r$ (no unit):

$$
r=\frac{\sum_{i=1}^{N}\left(O_{i}-\bar{O}\right) \cdot\left(P_{i}-\bar{P}\right)}{\sqrt{\sum_{i=1}^{N}\left(O_{i}-\bar{O}\right)^{2} \cdot \sum_{i=1}^{N}\left(P_{i}-\bar{P}\right)^{2}}}
$$

Index of Agreement (no unit, range $[0,1])$ :

$$
I A=1-\frac{\sum_{i=1}^{N}\left(P_{i}-O_{i}\right)^{2}}{\sum_{i=1}^{N}\left(\left|O_{i}-\bar{O}\right|+\left|P_{i}-\bar{O}\right|\right)^{2}}
$$

SKill VARiance (no unit):

$$
S K V A R=\frac{\sigma_{P}}{\sigma_{O}}
$$

Fraction of predictions within a Factor $\underline{\text { Of }} \underline{2}$ of observations (no unit, in \%):

$$
F O 2=\left(\frac{1}{N} \sum_{i=1}^{N} i \mid\left(0.5 \leq \frac{P_{i}}{O_{i}} \leq 2\right)\right) \cdot 100
$$

where the means of $N$ predictions and observations are defined as:

$$
\begin{aligned}
& \bar{P}=\frac{1}{N} \sum_{i=1}^{N} P_{i} \\
& \bar{O}=\frac{1}{N} \sum_{i=1}^{N} O_{i}
\end{aligned}
$$

respectively; and the standard deviations of $N$ predictions and observations are defined as:

$$
\begin{gathered}
\sigma_{p}=\sqrt{\frac{1}{N} \sum_{i=1}^{N}\left(P_{i}-\bar{P}\right)^{2}} \\
\sigma_{O}=\sqrt{\frac{1}{N} \sum_{i=1}^{N}\left(O_{i}-\bar{O}\right)^{2}}
\end{gathered}
$$

respectively.
Editorial responsibility: Filippo Giorgi, Trieste, Italy
Submitted: December 8, 2010; Accepted: November 30, 2011 Proofs received from author(s): June 19, 2012 